University of Wollongong

Research Online

Faculty of Engineering and Information

Faculty of Engineering and Information

Sciences - Papers: Part A

Sciences

$1-1-2015$

Power generation analysis of PowerWindow, a linear wind generator, using computational fluid dynamic simulations

Seyed A. Jafari

University of Wollongong, sahj551@uowmail.edu.au

Farzad Safaei

University of Wollongong, farzad@uow.edu.au

Buyung Kosasih

University of Wollongong, buyung@uow.edu.au

K C. Kwok

University of Western Sydney

Follow this and additional works at: https://ro.uow.edu.au/eispapers

Part of the Engineering Commons, and the Science and Technology Studies Commons

Research Online is the open access institutional repository for the University of Wollongong. For further information contact the UOW Library: research-pubs@uow.edu.au 


\title{
Power generation analysis of PowerWindow, a linear wind generator, using computational fluid dynamic simulations
}

\author{
Abstract \\ A new linear wind generator (LWG), named PowerWindow, is introduced. The modular and scalable LWG \\ is capable of generating power in low wind velocity condition, and hence can be an effective and safe \\ power generator in built environments. The aerodynamic mechanism of the LWG power generation is \\ elucidated using computational fluid dynamic (CFD) simulations, and the results are validated against the \\ experimental data obtained from the prototype wind tunnel tests. The simulations provide important \\ insights into the flow field in and around LWG particularly over the front and rear blades and how each one \\ contributes to the power generation. This study shows that PowerWindow can generate power with an \\ acceptable coefficient of performance $(C P \approx 0.15)$ in very low linear velocity ratio $(\lambda \approx 0.2)$, which is not \\ achievable in most conventional wind turbines at comparable size.

\section{Keywords} \\ wind, linear, simulations, powerwindow, power, dynamic, generator, analysis, fluid, computational, \\ generation \\ Disciplines \\ Engineering | Science and Technology Studies

\section{Publication Details} \\ S. A. H. Jafari, F. Safaei, B. Kosasih \& K. C. S. Kwok, "Power generation analysis of PowerWindow, a linear \\ wind generator, using computational fluid dynamic simulations," Journal of Wind Engineering and \\ Industrial Aerodynamics, vol. 147, pp. 226-238, 2015.
}




\title{
Power Generation Analysis of PowerWindow, a Linear Wind Generator, using Computational Fluid Dynamic Simulations
}

\author{
S. A H. Jafari ${ }^{\mathrm{a}, *}$, F. Safaei ${ }^{\text {a }}$, B. Kosasih ${ }^{\text {b }}$, K.C.S. Kwok ${ }^{\text {c }}$ \\ ${ }^{a}$ School of Electrical, Computer and Telecommunications Engineering, University of \\ Wollongong, Wollongong, NSW 2500, Australia \\ ${ }^{\mathrm{b}}$ School of Mechanical, Materials and Mechatronic Engineering, University of Wollongong, \\ Wollongong, NSW 2500, Australia \\ ${ }^{\mathrm{c}}$ Institute for Infrastructure Engineering, University of Western Sydney, Penrith, NSW 2751, \\ Australia \\ *e-mail:sahj551@uow.edu.au (Corresponding Author)
}

\begin{abstract}
A new linear wind generator (LWG), named PowerWindow, is introduced. The modular and scalable LWG is capable of generating power in low wind velocity condition, and hence can be an effective and safe power generator in built environments. The aerodynamic mechanism of the LWG power generation is elucidated using computational fluid dynamic (CFD) simulations, and the results are validated against the experimental data obtained from the prototype wind tunnel tests. The simulations provide important insights into the flow field in and around LWG particularly over the front and rear blades and how each one contributes to the power generation. This study shows that PowerWindow can generate power with an acceptable coefficient of performance $\left(C_{P} \approx 0.15\right)$ in very low linear velocity ratio $(\lambda \approx 0.2)$, which is not achievable in most conventional wind turbines at comparable size.
\end{abstract}

Keywords: coefficient of performance, computational fluid dynamics, linear wind generator, PowerWindow, transition - turbulence model 


\section{Introduction}

Conventional wind turbine designs can be grouped into two types, horizontal axis wind turbine (HAWT) and vertical axis wind turbine (VAWT). The coefficient of performance $\left(C_{P}\right)$ of HAWT has been reported to be up to 0.5 , while that of an efficient VAWT is 0.4 [1]. $C_{P}$ shows the ratio of the power captured by the generator to the entire wind energy passing through its swept area as shown in Equation (1).

$C_{P}=\frac{P_{\text {captured }}}{P_{\text {wind }}}=\frac{P_{\text {captured }}}{1 / 2\left(\rho V_{\text {wind }}^{3}\right)}$

Linear wind power generator $(\mathrm{LWG})$ is a new generation of wind based power generator device. In LWGs, blades form two planes moving in opposite directions perpendicular to the incoming wind. Variable-geometry oval-trajectory (VGOT) Darrieus turbine [2] which was basically a modified version of a Straight-blade Darrieus or H-rotor VAWT [3], could be considered as the first developed LWG.

The VGOT blades move on rail tracks located in an elevated position, instead of rotating around a single rotor shaft. The blades are mounted on wheels which are coupled to electrical power generators. As reported, at the optimum design configuration its coefficient of performance can Reach up to $0.57[4,5]$. The results demonstrated that a turbine with a higher number of blades $(N=120-160)$ has a good efficiency at a tip speed ratio (TSR) $\sim 2$, while at higher TSR, a turbine with fewer blades $(N=60-80)$ has a better efficiency.

One type of LWG, named PowerWindow, is currently being developed at the University of Wollongong, Australia. A prototype of this LWG was built and tested in a wind tunnel - see Figure 1(a). PowerWindow is a new LWG design utilizing a linear cascade blade configuration, plus having scalability with respect to technology, manufacturing and cost because the modules can be mass produced and then assembled and modularised on site. 
The computational fluid dynamic (CFD) model of PowerWindow has been developed in this study and validated by the prototype which had earlier been tested in the wind tunnel. The aim of this paper is to present an analysis on power generation mechanism of PowerWindow, using the (CFD) simulations.

\section{Description of PowerWindow}

Figure 1(a) shows a sketch of the PowerWindow prototype. A PowerWindow module is composed of a light frame that could be mounted on the support tower or structural frame. A couple of rotating disks connected together with a shaft are mounted at the top and bottom of side frame. The generator is attached to the bottom shaft. There are two chains running over these disks and several blades of appropriate profile are attached to the chain. For the direction of wind shown in the Figure, the blades that encounter wind first are referred to as 'upwind' or 'front' blades and the ones behind are referred to as 'downwind' or 'rear' blades.

The wind will exert a lift force on the blades causing the belt to roll (similar to a garage door opening or closing). As the belt goes around, the blades change side and orientation as shown in Figure 1(b). It is clear that if the attachment between blades and the belt were fixed, the lift forces acting on the front and the rear planes oppose each other. Hence PowerWindow is designed such that blades 'flip over' and adjust their angle of attack as they move from one plane to another. The adjustment is done passively without any additional control mechanism. This is achieved by observing that the force of gravity acts at the centre of mass, while the lift force acts at the centre of pressure which for most profiles is closer to the leading edge of the blade. In PowerWindow, the blade is attached to the belt at a point which is forward of the centre of mass but behind the centre of pressure in the upwind state. In the current prototype and based on the blade profile shown, the point of attachment is at about a third of the chord length. The blade is free to rotate around within a certain degree at the point of attachment so that a positive and negative angle of attack can be 
obtained in the front and rear blades respectively. The blade's angular rotation is constrained by a simple pin-and-groove mechanism shown in Figure 1(b), which in the current prototype limits the angles of attack to $\pm 16^{\circ}$.

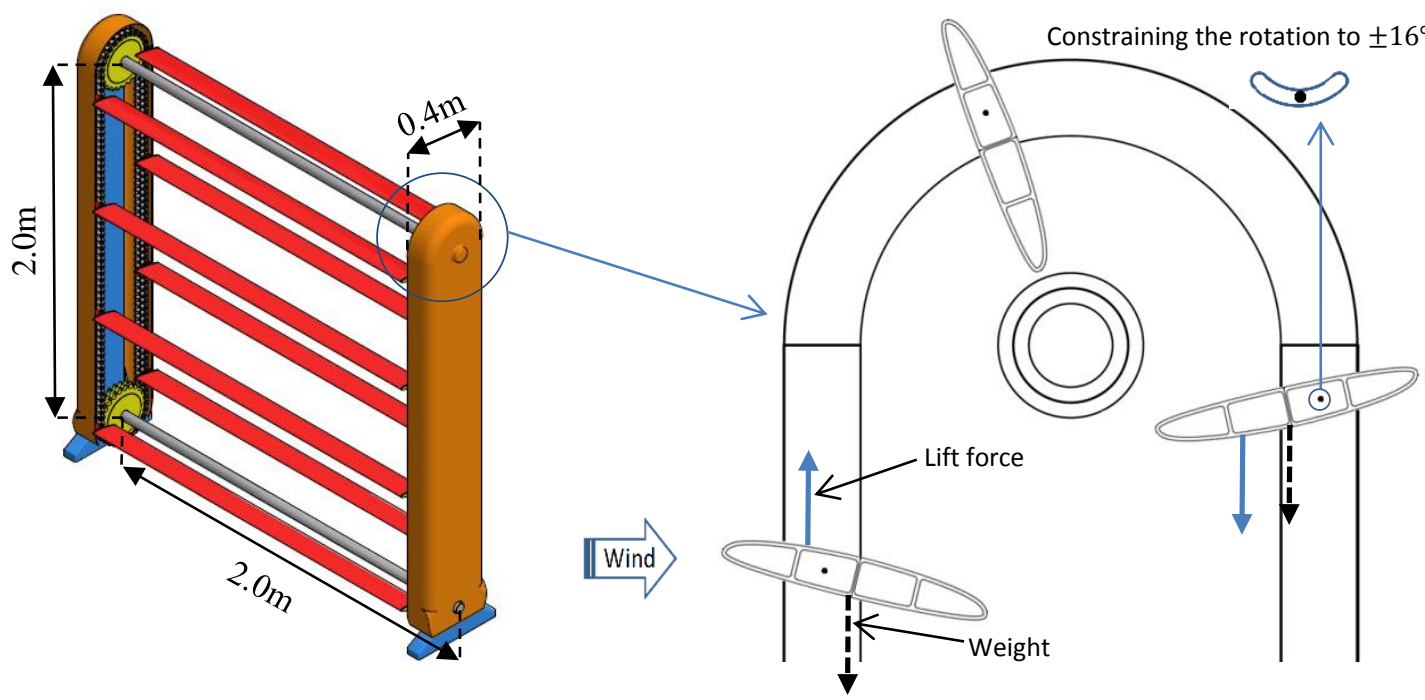

(a)

(b)

Figure 1 (a) Sketch of the PowerWindow prototype, (b) Blades changing their side and orientation at the top of PowerWindow.

Despite the freedom of a blade to rotate within these limits, the combination of weight and lift force create a pitch moment that keeps the blade fixed in the appropriate angle of attack without any 'flapping'. This was verified during the actual tests of the device as reported in [6]. The angle of attack is also automatically adjusted as the blade changes orientation at the top and bottom of the module. Note that a directionally sensitive device is needed to yaw PowerWindow. However, due to front-rear symmetry, the yaw motion to orient PowerWindow towards the wind is only required to be within $180^{\circ}$ range. For large towers, it is envisaged that the yaw motion could also be applied to individual rows of modules, or a subset thereof, rather than the whole plant (see Figure 2). 

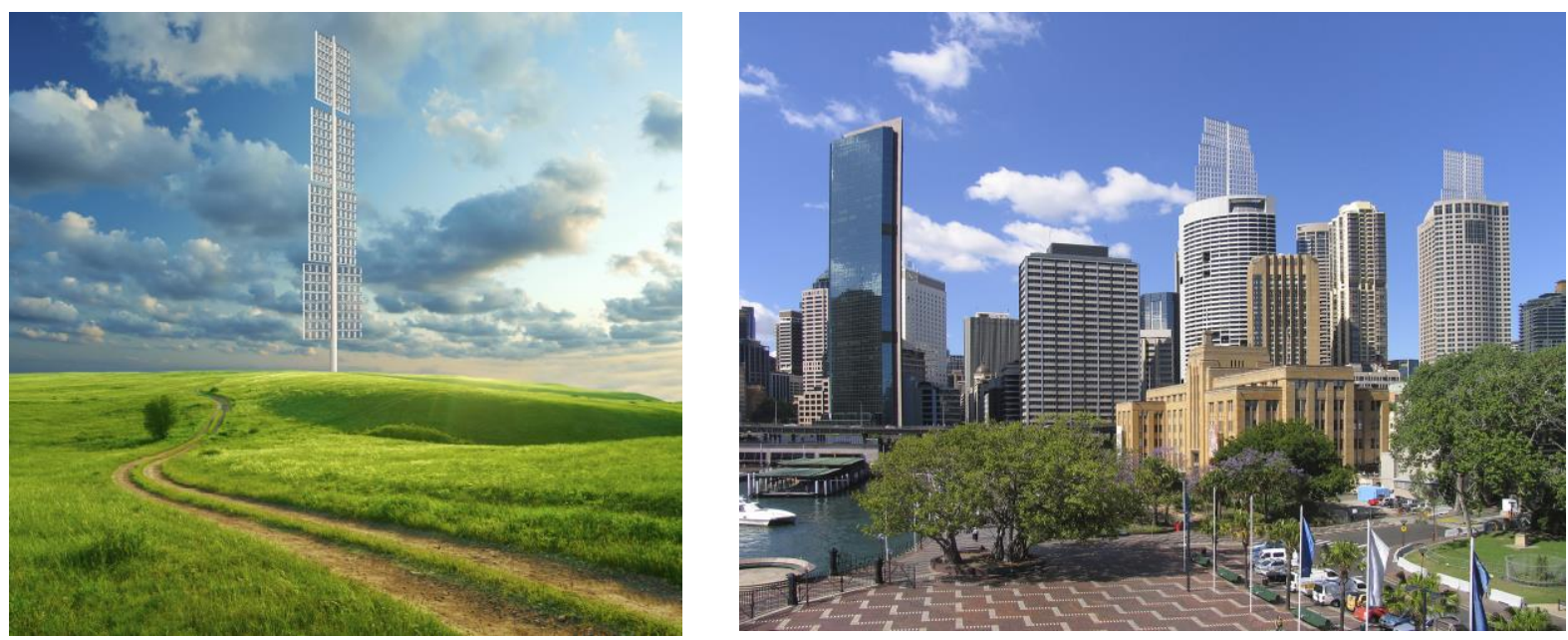

Figure 2 An artist impression of installations of PowerWindow modules on a tower or on top of buildings.

The opposite translational direction of the front and rear blades and their contribution in the power generation is a characteristic of PowerWindow which is very similar to a counter rotating wind turbine (CRWT). CRWT is a HAWT having two rotors rotating in opposite directions around the same axis [7]. It has been found that in CRWT, the front rotor affects the flow by increasing the effective angle of attack over the rear rotor blades, and consequently enhances the rear blades power generation $[8,9]$. The aerodynamic characteristics of a CRWT with that of a single rotor having equal solidity as well as a single rotor having half solidity has been studied [10]. It has been shown that the CRWT efficiency is $30 \%$ more than a single rotor having half solidity and $5 \%$ less than a single rotor having equal solidity. The main difference between PowerWindow and CRWT mechanism is that PowerWindow front and rear blades mandatorily move at the same velocity while CRWT rotors can freely rotate with different rotational velocities.

Another important characteristic of PowerWindow is that its blades do not rotate, but linearly move in air, hence every section of the blade faces a uniform wind velocity and consequently has an equal efficiency without being twisted (unlike HAWTs and most of VAWTs). In addition, PowerWindow edges are covered and kept out of the wind so that the tip vortices are non-existent to interfere with neighboring modules. These features allow construction of a large PowerWindow 
plant where the modules can be placed next to (beside, on the top or below) each other without a significant loss of efficiency due to the generation of tip vortices. The dynamic forces exerted on each PowerWindow module in a plant is small and is not synchronized with each other, which allows the modules to be designed so that each one operates independently at its optimum condition.

In addition to these technical features, the form factor of PowerWindow, which resembles a rectangular window with a sparse venetian blind, may make it easier to integrate this device in built areas in a way that is aesthetically acceptable as shown in Figure 2.

Despite the beneficial features of PowerWindow, the fundamental mechanism and hence the prototype optimum power generation capacity have not been studied. This paper investigated the flow field and the resultant pressure distribution around the PowerWindow blades with the aim of understanding and optimising the device's power generation capability. This paper reported the results of the first stage of the investigation based on the current design, which is earmarked for further research and development to gain a fundamental understanding of the mechanism and particularly optimization of PowerWindow' power generation capacity. 


\section{Experimental Model Setup}

A PowerWindow prototype was constructed through collaboration of University of Wollongong and Birdon Pty Ltd [11]. This prototype was tested in the Monash University wind tunnel's $12 \mathrm{~m}($ Length $) \times 9 \mathrm{~m}($ Width $) \times 5 \mathrm{~m}($ Height $)$ test section [12]. The wind tunnel is equipped with two $5 \mathrm{~m}$ diameter fans driven by 4 AC motors, with a total power of $1.2 \mathrm{MW}$, which are controlled by a thyristor controller to produce variable speed in the wind tunnel test section up to $50 \mathrm{~m} / \mathrm{s}$ air velocity. This prototype has $2 \mathrm{~m} \times 2 \mathrm{~m} \times 0.4 \mathrm{~m}$ dimensions as shown in Figure 1 (a). This model has 12 blades, and each blade has $2 \mathrm{~m}$ span length, $150 \mathrm{~mm}$ chord length and $23 \mathrm{~mm}$ thickness. Considering that 5 blades are simultaneously located in each plane, the swept area of front/rear plane is $3.5 \mathrm{~m}^{2}$, while each blade has $0.3 \mathrm{~m}^{2}$ area. As a result, the solidity $(\sigma)$ of the model is 0.428 $(\sigma=0.428) . \sigma$ shows a relation between number of the blades $\mathrm{N}$, plan area of each blade $\mathrm{B}$, and the blade and rotor swept area A, and is defined in Equation (2) for PowerWindow.

$\sigma=\frac{N B}{A}$

Table 1 Major dimensions of the shrouded wind turbine model.

\begin{tabular}{c|c|c|c}
\hline & Dimension & Value & Units \\
\hline $\begin{array}{c}\text { PowerWindow } \\
\text { prototype }\end{array}$ & Length L & 2 & $\mathrm{~m}$ \\
& Width W & 2 & $\mathrm{~m}$ \\
\hline \multirow{2}{*}{ Blade } & Depth D & 400 & $\mathrm{~mm}$ \\
& Span S & 2 & $\mathrm{~mm}$ \\
& Chord C & 150 & $\mathrm{~mm}$ \\
& Thickness T & 23 & degrees \\
\hline
\end{tabular}


A cross section of the PowerWindow blade is shown in Figure 3. The reason for using a symmetrical blade is to have an almost equal effectiveness in power generation in both front and rear blades. Figure 4 shows the Lift $\left(C_{L}\right)$ and drag $\left(C_{D}\right)$ coefficients of the PowerWindow blade extracted for a limited range of angle of attacks $(\alpha)$ and Reynolds number of PowerWindow operating condition using CFD simulations. The inlet wind velocity was set to $8 \mathrm{~ms}-1$, which results in the Reynolds number of $7.1 \times 10^{4}$, based on flow over a flat plate.

\section{$150 \mathrm{~mm}$}

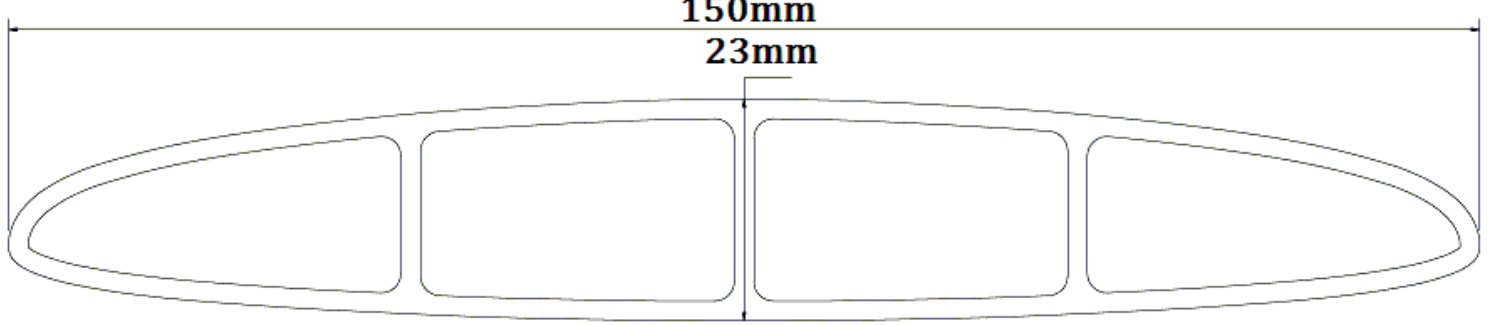

Figure 3 Cross section view of PowerWindow blade showing chord C and thickness T.

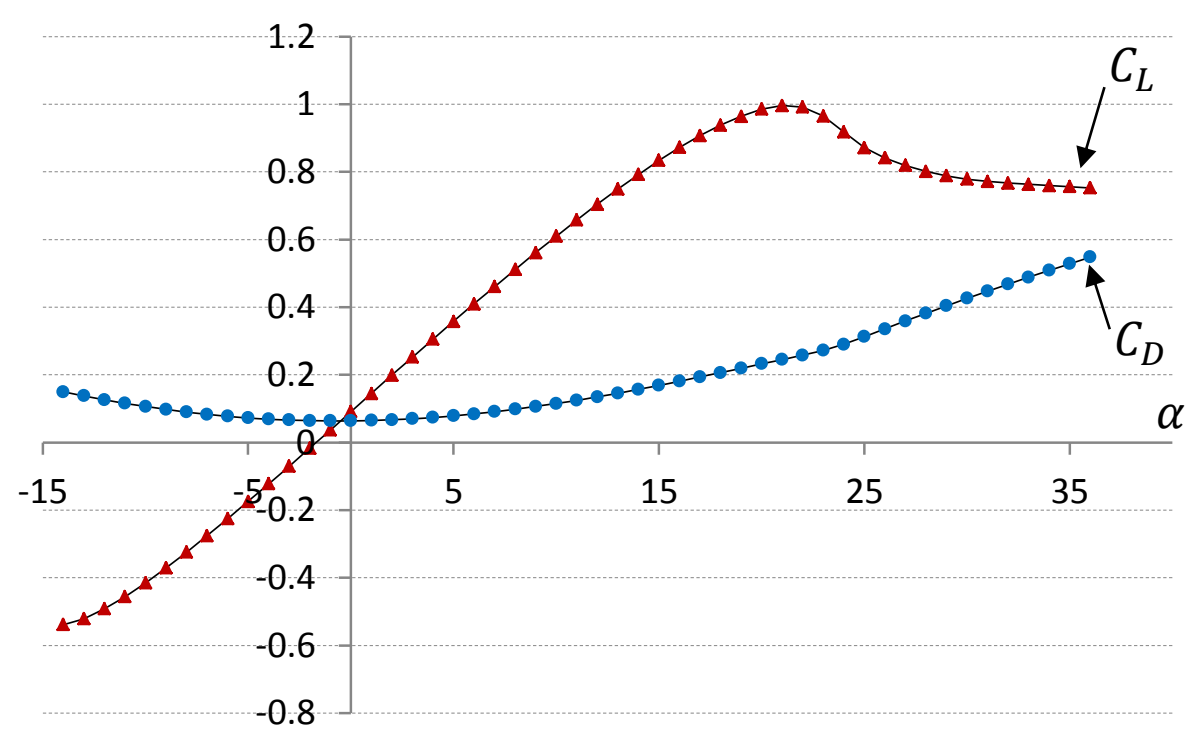

Figure $4 C_{L}$ and $C_{D}$ of the PowerWindow blade extracted for $-14<\alpha<36$ and Reynolds number of $7.1 \times 10^{4}$. 
Design angle $\left(\theta_{0}\right)$ presents the angle between the chord line of the blade when travelling linearly up/down within the planes and the horizontal axis, which was set to $16^{\circ}\left(\theta_{0}=16^{\circ}\right)$. The major dimensions of PowerWindow prototype and its blades are given in Table 1.

The prototype was placed in a Monash University wind tunnel's with working section of $12 \mathrm{~m}$ $\times 9 \mathrm{~m} \times 5 \mathrm{~m}$ and tested atwind speeds up to $8 \mathrm{~ms}^{-1}$. As shown in Figure 5 (a) the prototype was placed on the floor of the wind tunnel and a small ramp was installed at its bottom inlet. As the wind flows over the blades the induced lift forces the front/rear blades up/down and produces torque on the two rotating disks at the bottom of the frame which turns the rotor connected to the bottom disks, as shown in Figure 5 (a).

A torque sensor was attached to the shaft to measure the output power. A variable electrical load and associated power electronics were also developed to measure the electrical output power produced by the generator (after accounting for the losses due to gearbox and generator). However, unfortunately, the torque sensor showed some instability in its readings during the test, so in this paper only the electrical output power is considered. The output power was measured and recorded against time for a range of speeds. At a test wind speed of $8 \mathrm{~ms}^{-1}$ the measured electrical output power is shown in Figure 5 (b). As can be seen, the maximum electrical power generated by the prototype for this configuration is around $140 \mathrm{~W}$, which corresponds to a coefficient of performance of almost $0.15\left(C_{P}=0.15\right)$. 


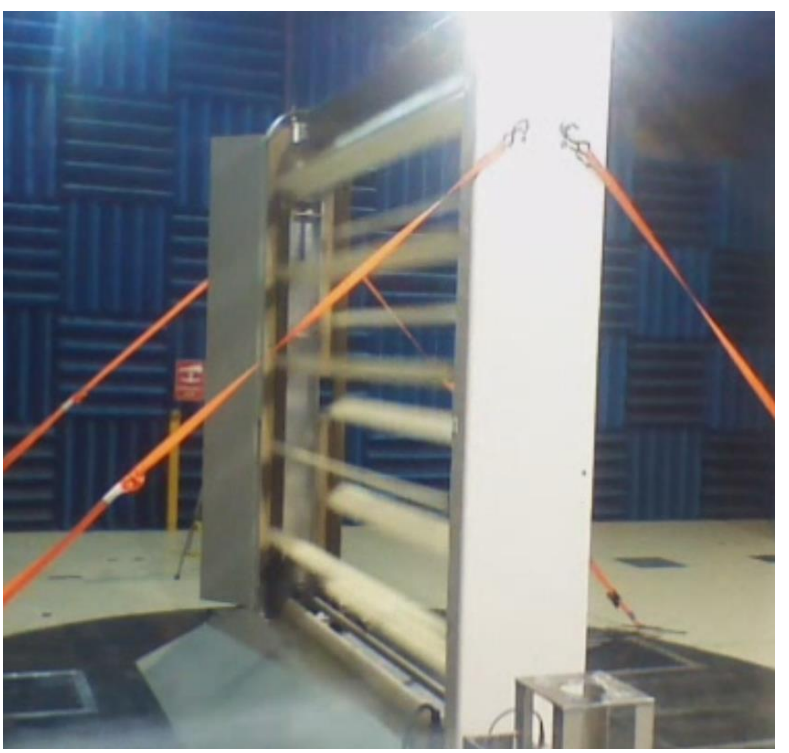

(a)

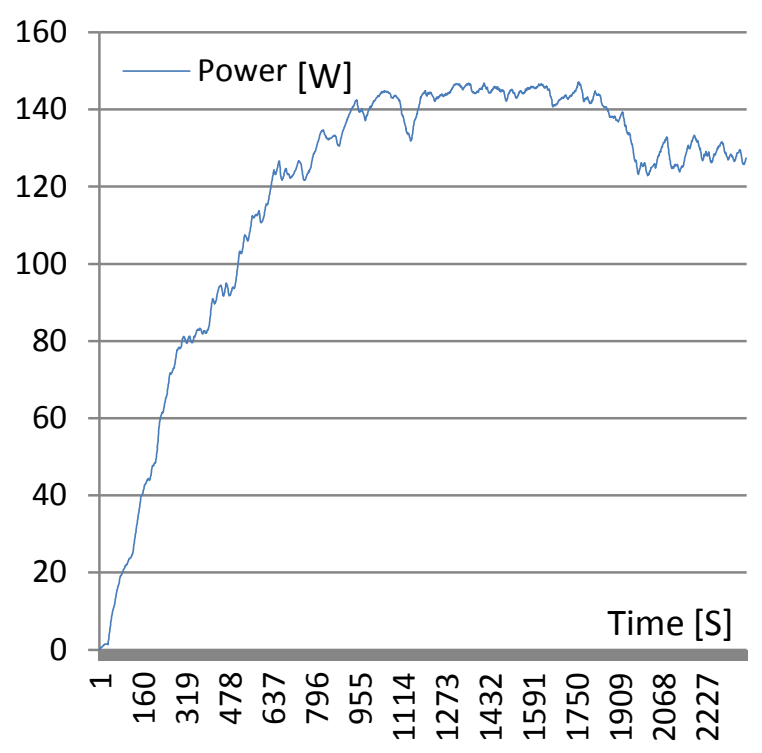

(b)

Figure 5 (a) Prototype of PowerWindow in wind tunnel (when $\sigma=0.428$ and $\theta_{0}=16$ ), and (b) Power generation versus time.

The linear velocity of the blades has been measured within $1.5 \mathrm{~ms}^{-1}$ and $2.0 \mathrm{~ms}^{-1}$ resulting in linear velocity ratio between 0.1875 and $0.25(0.1875<\lambda<0.25) . \lambda$ is the ratio of the LWG blade absolute velocity, which is also equal to their vertical velocity, to the wind velocity as shown in Equation (3).

$\lambda=\frac{V_{\text {blade }}}{V_{\text {wind }}}=\frac{V_{y, \text { absolute }}}{V_{\text {wind }}}$ 


\section{CFD Model Setup}

\subsection{Transition - Turbulence model}

CFD is a numerical calculation of the underlying equations to predict physical phenomena such as flow and heat conduction in a flow [13]. The three-dimensional (3D) CFD simulations solving the Navier-Stokes equations are quite accurate, but computationally expensive [14]. The CFD simulations can give explicit modelling of turbine blades and estimate the complex turbulent flows adjacent to its blades and wake regions created at the far downstream [15]. A 2D CFD model of the PowerWindow prototype has been created in this study. Since the PowerWindow blades move in a linear trajectory, the cross flow along the length of the blades can be ignored, and hence 2D CFD model is sufficiently reliable here.

Selecting an appropriate model for CFD simulation is very important since not every model predicts the separation phenomenon precisely. Separation from the blade surface greatly affects the performance of PowerWindow by changing the lift force exerted on them Although the prototype was not subjected to high wind velocities and is operating at very low $\lambda$, based on flow over a flat

plate, Reynold number $\left(7.1 \times 10^{4}\right)$ indicated high turbulent flow over the blades [16]. However, vorticity is also expected to be high around the blades because the front and rear blades are moving in opposite direction with a relatively short separation distance $(250 \mathrm{~mm})$, thus affecting the adjacent flow to their boundaries.

On the other hand, because the prototype is installed on the ground, each blade might be subjected to: (a) a different incoming wind velocity magnitude based on its elevation from the ground; and (b) a different incoming wind velocity direction, based on its distance from the ramp located at its bottom inlet, as can be seen in Figure 6 (a) and (b) respectively. This figure shows PowerWindow prototype against the incoming wind in a wind tunnel, inside the axial stream tube. 


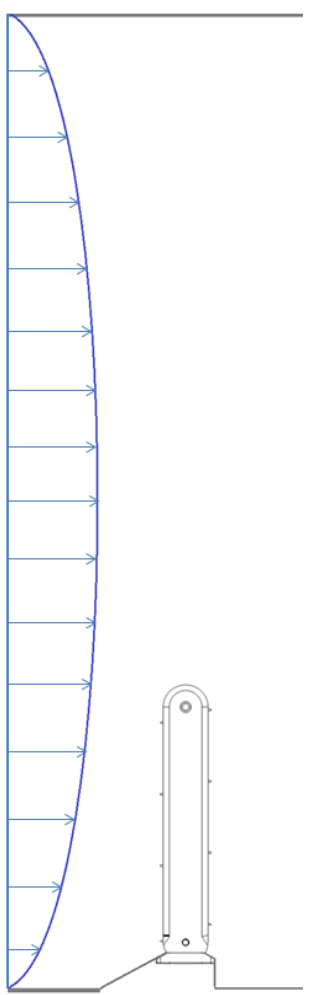

(a)

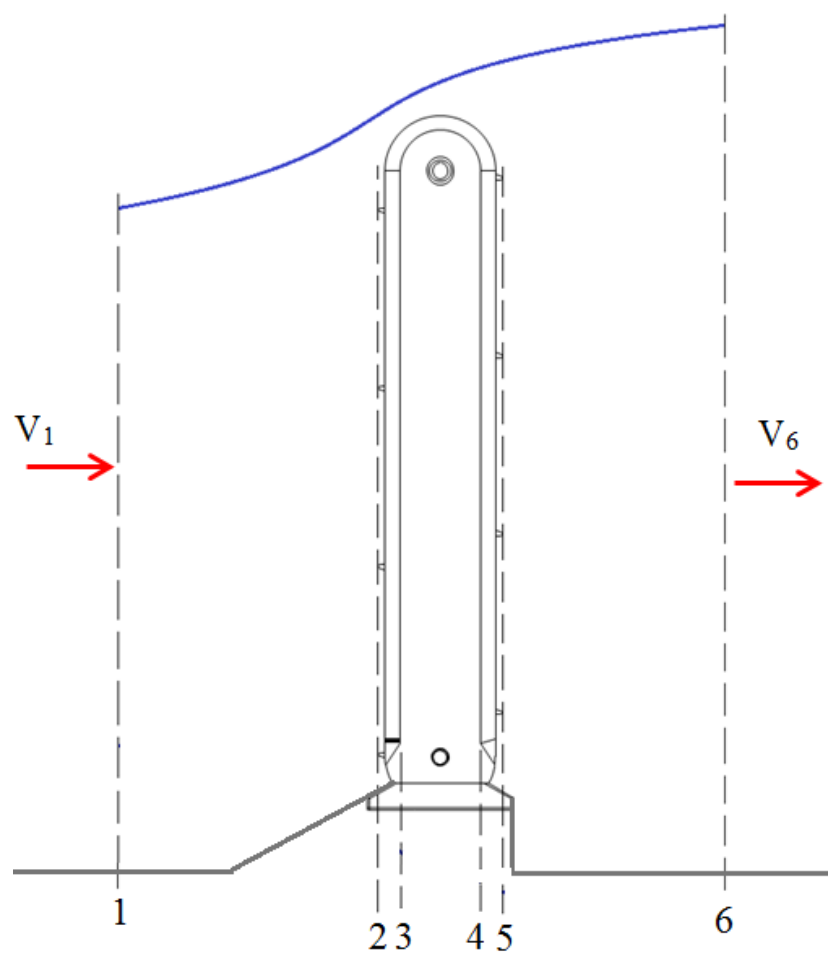

(b)

Figure 6 PowerWindow prototype (a) against the incoming wind in a wind tunnel, and (b) inside the axial stream tube.

The Shear Stress Transport (SST) model has been validated extensively for separating 2D flows with Reynolds-averaged Navier-Stokes (RANS) models [17]. Menter [18] showed the SST model outperforms the 4-equation, v2-f (transition SST) model in predicting separating velocity profiles for the NACA 4412 blade case [19]. Unlike the SST 7-equation Reynolds stress model (RSM), the $\nu 2-f$ and low-Re k- $\varepsilon$ models use the data for an asymmetric planar diffuser as presented in [20]. The v2-f model gave the best prediction of the separation point. Menter [18] suggested that flow over the rotor blades can be subject to significant region of laminar-turbulence transition and because the transition process can affect the separation behavior of the boundary layer on the blade surface, the $v 2$-f model is the best model in case of separation, and has thus been selected for this study. 
FLUENT 14.5 has been used for simulation of the CFD model in this study. This model is a modified SST $k$ - $\omega$ RANS turbulence model by the addition of two other transport equations for $\gamma$ (the intermittency) and the transition onset criteria. The transport equation for $\gamma$ is defined as

$$
\frac{\partial(\rho \gamma)}{\partial t}+\frac{\partial\left(\rho U_{j} \gamma\right)}{\partial x_{j}}=P_{\gamma 1}-E_{\gamma 1}+P_{\gamma 2}-E_{\gamma 2}+\frac{\partial}{\partial x_{j}}\left[\left(\mu+\frac{\mu_{t}}{\sigma_{y}}\right) \frac{\partial \gamma}{\partial x_{j}}\right]
$$

Where $t$ is time (s), $\rho$ is air density $\left(\mathrm{kg} \mathrm{m}^{-3}\right), U$ is velocity of air $\left(\mathrm{m} \mathrm{s}^{-1}\right), P$ is pressure (Pa) and $\mu$ is molecular viscosity ( $\mathrm{Pa} \mathrm{s}$ ) and the second transport equation for the transport of the transition momentum thickness Reynolds number, $\tilde{R} e_{\theta e}$ (local transition onset momentum thickness Reynolds number) is

$$
\frac{\partial\left(\rho \tilde{\operatorname{R}} e_{\theta t}\right)}{\partial t}+\frac{\partial\left(\rho U_{j} \tilde{R} e_{\theta t}\right)}{\partial x_{j}}=P_{\theta t}+\frac{\partial}{\partial x_{j}}\left[\sigma_{\theta t}\left(\mu+\mu_{t}\right) \frac{\partial \tilde{R} e_{\theta t}}{\partial x_{j}}\right]
$$

These equations are coupled with the SST turbulence model

$$
\begin{aligned}
& \frac{\partial}{\partial t}(\rho k)+\frac{\partial}{\partial x_{j}}\left(\rho u_{j} k\right)=\widetilde{P}_{k}-\widetilde{D}_{k}+\frac{\partial}{\partial x_{j}}\left[\left(\mu+\sigma_{k} \mu_{t}\right) \frac{\partial k}{\partial x_{j}}\right] \\
& \frac{\partial}{\partial t}(\rho \omega)+\frac{\partial}{\partial x_{j}}\left(\rho u_{j} \omega\right)=\alpha \frac{P_{k}}{v_{t}}-D_{\omega}+C d_{\omega}+\frac{\partial}{\partial x_{j}}\left[\left(\mu+\sigma_{k} \mu_{t}\right) \frac{\partial \omega}{\partial x_{j}}\right] \\
& P_{k}=\gamma_{e f f} P_{k} \\
& \widetilde{D}_{k}=\min \left[\max \left(\gamma_{e f f}, 0.1\right), 1.0\right] D_{k}
\end{aligned}
$$

$P_{k}$ and $D_{k}$ are the turbulent kinetic energy production and destruction terms in the original SST turbulence model and $\gamma_{e f f}$ is the effective intermittency calculated by the additional two equations. Menter [18] expressed that this approach has two main advantages. The first is that it improves the robustness of the model because the intermittency does not enter directly into the momentum equations. The second advantage is that it allows the model to predict the effects of high free 
stream turbulence levels on buffeted laminar boundary layers. The reason is that for large free stream eddy viscosities, the small values of intermittency in the boundary layer do not cancel out the local eddy viscosity. Consequently, the increase in the laminar shear stress and heat transfer that has been observed experimentally in buffeted laminar boundary layers can in principle be captured by the present model. The transition SST model constants were kept as its default [21].

\section{2. Mesh structure and boundary conditions}

Higher mesh quality is achievable primarily by using finer and structured mesh. While as the number of elements is higher, the simulation speed is slower. Although structured mesh is preferred, it is difficult to generate a high quality structured mesh in the entire domain. In order to achieve a balance between solution accuracy and calculation time, a combination of structured and unstructured mesh is used. This technique helps to decrease the number of elements while having a high quality mesh around the body $[21,22]$. Therefore, rows of very fine structured rectangular elements are generated adjacent to the blade surface, as shown in Figure 7(c). The optimum number of these elements was also investigated. This structured region is connected to the outer structured region via unstructured triangular elements, as shown in Figure 7(b). Structured coarser mesh is used in the outer region as can be seen in Figure 7(a).

Increasing the number of elements results in decreasing solution speed. Hence a mesh independence study is done to find the optimum element structure over object boundaries. The mesh quality around the PowerWindow blade has been increased in three steps. 50 cells $(6 \mathrm{~mm})$ were initially generated around each blade. This number is increased to $100(3 \mathrm{~mm}), 200(1.5 \mathrm{~mm})$ and $400(0.75 \mathrm{~mm})$ in the subsequent steps. Figure 8 (a), (b), (c), and (d) show the element structure and size around the blade in each step, and the pressure distribution on the blades is investigated in each step. Figure 9 shows pressure value over the blade with different number of mesh elements over its boundary. This figure shows that the mesh with 50 and 100 cells on the 
blades are not reliable enough as the results are very far from the results achieved with 200 and 400 cells, while the result achieved by 200 cells is very close to 400 cells. This means that increasing the number of elements on the blades further than 200 does not improve the simulation results significantly. Hence using this mesh structure preserves the result accuracy.

The frame of the hybrid region containing the front and rear blades was selected as the multiple reference frame (MRF) which could move vertically within the domain. Therefore the boundaries of the blades are selected as moving wall with zero velocity relative to their adjacent cells and their vertical velocity used to be adjusted by the velocity of the MRF surrounding cells. The inlet boundary condition had a constant free stream velocity of $8 \mathrm{~m} . \mathrm{s}^{-1}$ and the outlet boundary of the domain is set to atmospheric pressure. Turbulence intensity of $5 \%$ and turbulence viscosity ratio of 10 (as default) were set for both inlet and outlet boundary conditions. The standard pressure correction method and a first order upwind scheme was used. The top and bottom boundaries of the domain were selected as stationary wall. In order to measure $C_{P}$ for various conditions, $\lambda$ was changed from 0.025 to $0.4(0.025<\lambda<0.4)$ with increment of 0.025 . Gambit [23] has been used as the mesh generation tool in this study.

Both the wind tunnel test model and the numerical mode used in the CFD simulations were at prototype scale, thus avoiding the need to accommodate any scaling dictated by similarity criteria. 


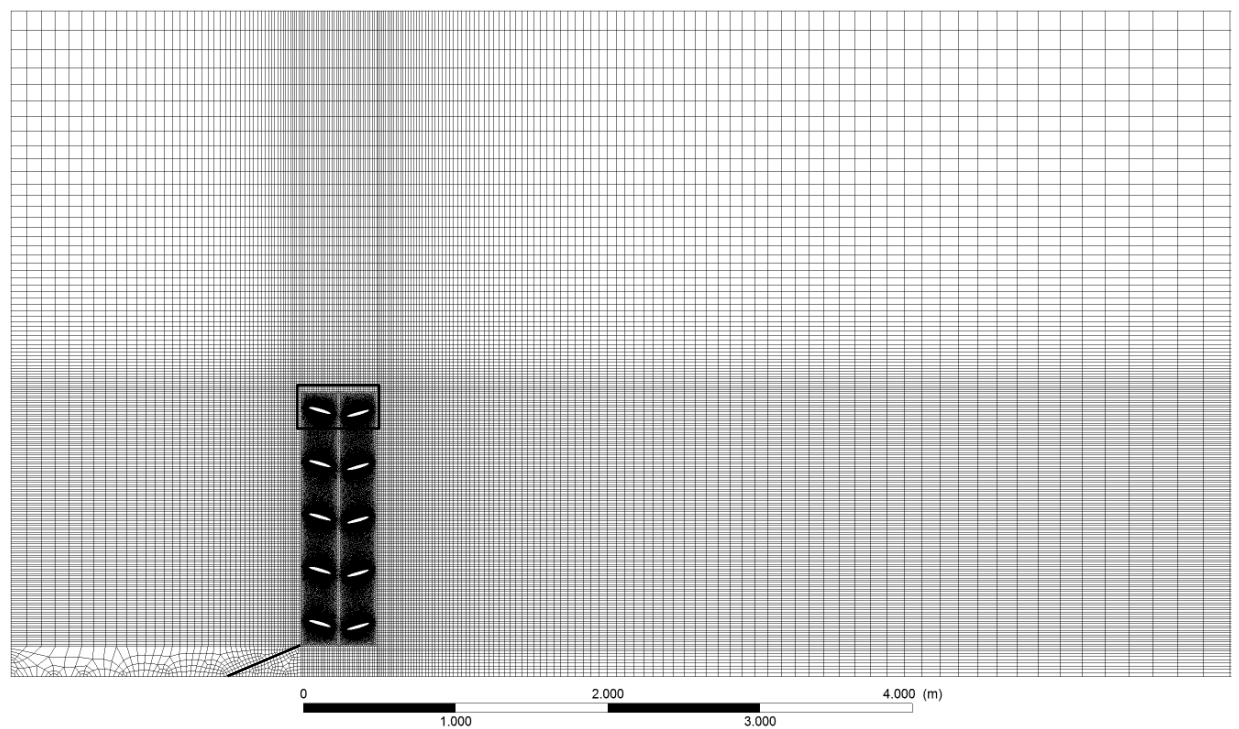

(a)

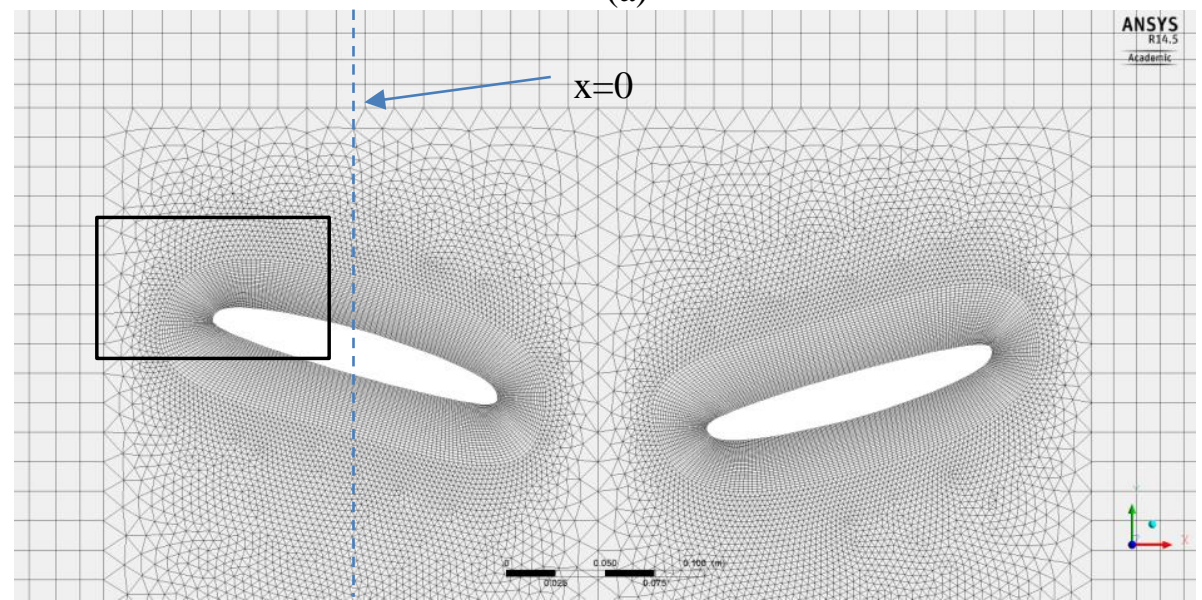

(b)

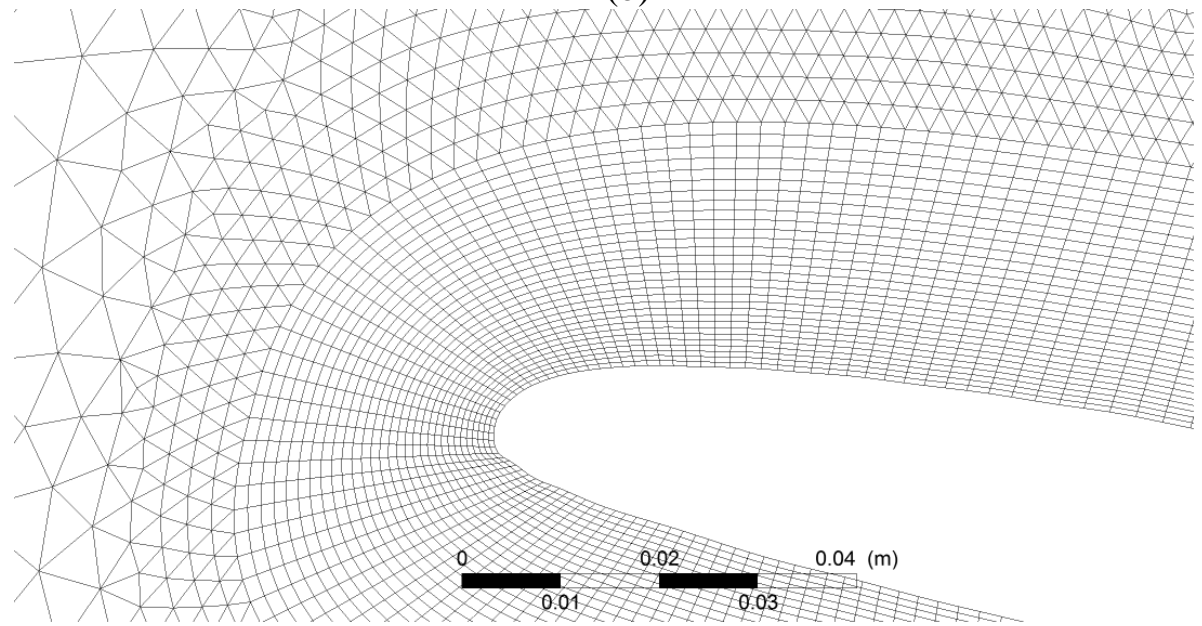

(c)

Figure 7 (a) Structured mesh generated around the unstructured region. (b) Combination of structured and unstructured mesh around the blades (the blue dash line shows $x=0$ ). (c) Very fine structured rectangular elements adjacent to the blade surface. 


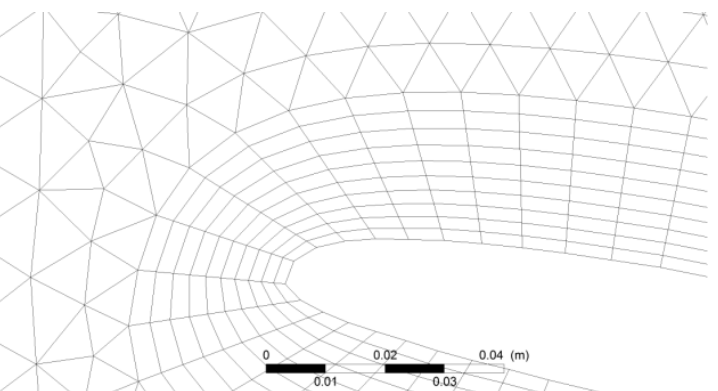

(a)

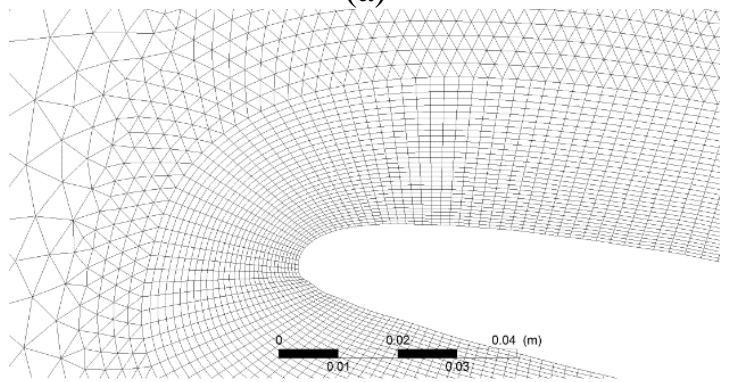

(c)

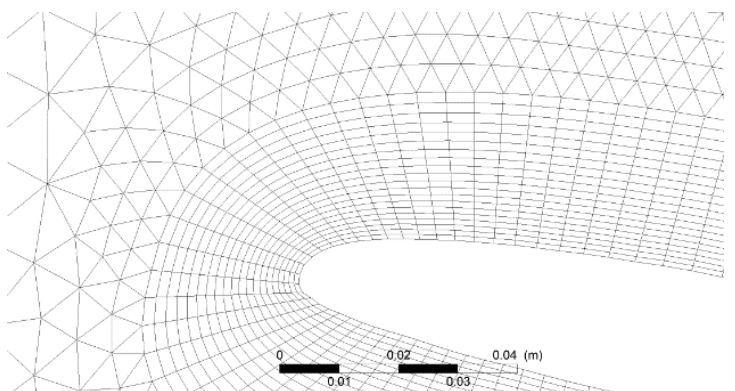

(b)

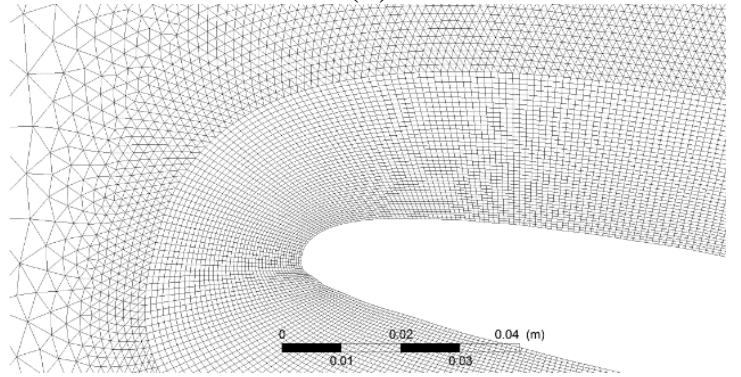

(d)

Figure 8 Mesh generated around the PowerWindow blade with (a) 50 cells, (b) 100 cells, (c) 200 cells and (d) 400 cells.

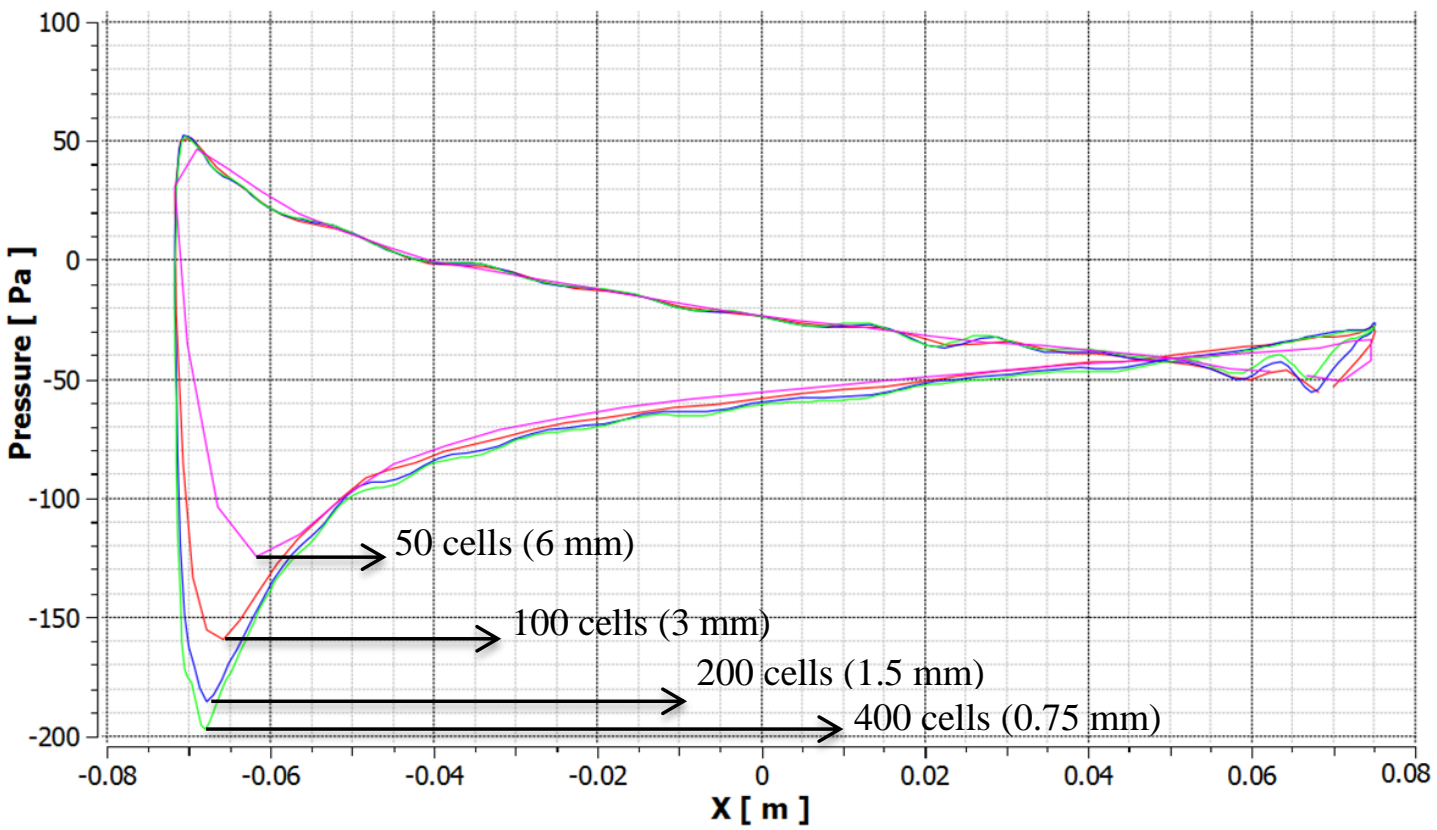

Figure 9 Pressure value over the blade when surrounded by different number of cells. Location of $x=0$ has been shown in Figure 7 (b) with the blue dash line. 
The operation velocity as determined by $\lambda$ cannot be predicted in the CFD model. Therefore, the model needs to simulate the LWG (or any other wind turbine) and calculate its power generation in a range of $\lambda$. Power generation has a semi-parabolic relation with $\lambda$, so that it increases as $\lambda$ increases, till it reaches the optimum value. Beyond this point the power generation decreases by increasing $\lambda$ (because of the decrease in the angle of attack created over the blades). The optimum $\lambda$ predicted by the CFD model approximates the operating velocity. However, the actual operating velocity of the device is usually lower than what predicted by the CFD model, because of the effect of friction and other losses. 


\section{Results and Discussion}

\subsection{Coefficient of performance of the PowerWindow prototype}

For verification of the results achieved by the CFD model of PowerWindow, the model has been built with $\sigma=0.428$ and $\theta_{0}=16^{\circ}$ (similar to the prototype). The CFD model has been tested in four different poses shown in Figure 10. In each pose $L_{0}$ shows the elevation of the front blade to its adjacent rear blade. The $L_{0} / C$ ratio is $2 / 3,1 / 3,0$ and $-1 / 3$ respectively in pose $\mathrm{A}, \mathrm{B}$, $\mathrm{C}$ and $\mathrm{D}$ while the chord length of each blade is $15 \mathrm{~cm}(C=15 \mathrm{~cm})$. This approach allows the relation between the power generation performance of PowerWindow and position of the front blades to the rear ones investigated.

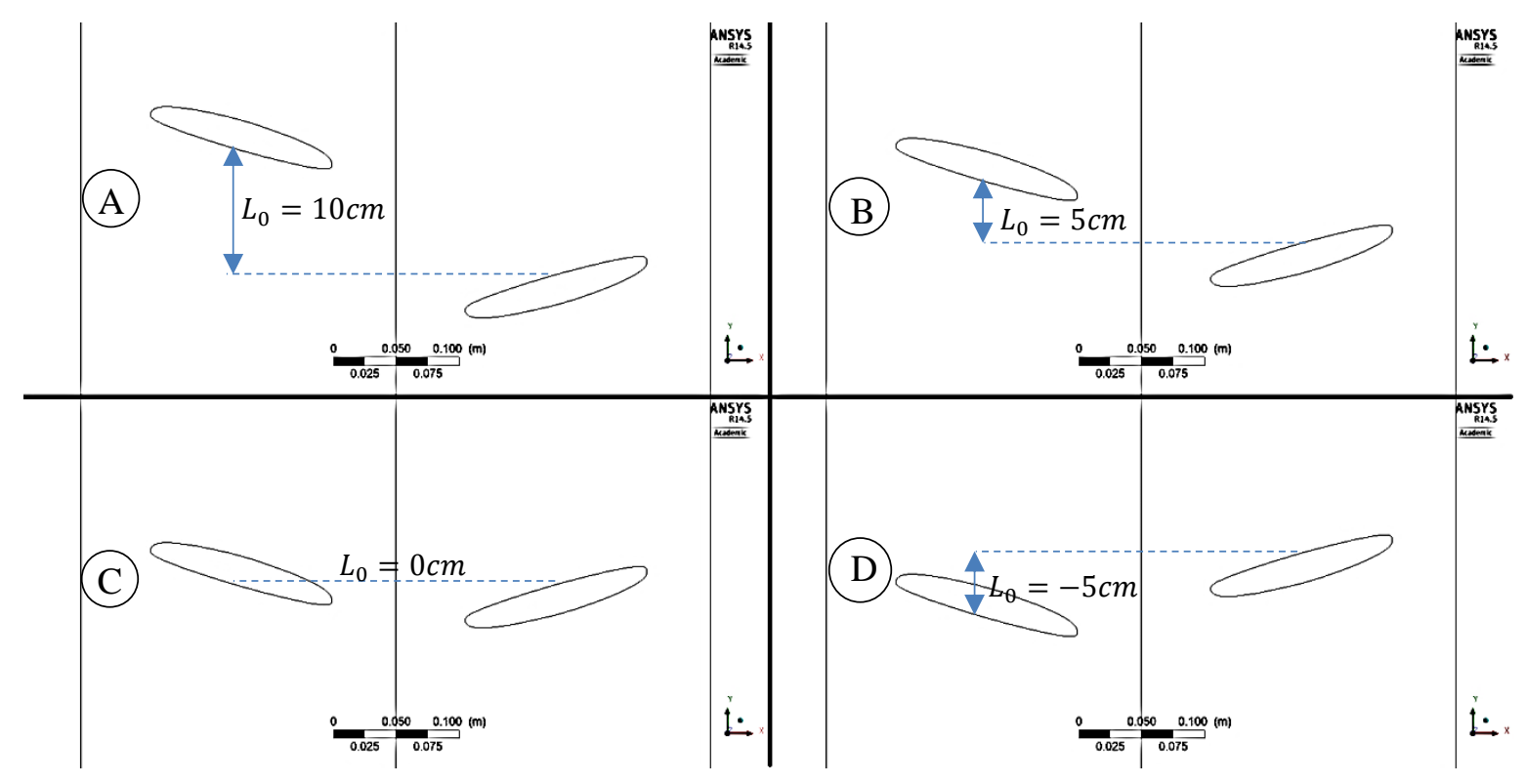

Figure 10 Front and rear blades of the PowerWindow CFD model in poses A when $L_{0} / C=2 / 3, \mathrm{~B}$ when $L_{0} /_{C}=1 / 3, \mathrm{C}$ when $L_{0} / C=0$ and D when $L_{0} / C=-1 / 3(C=15 \mathrm{~cm})$.

The vertical and horizontal forces exerted on the front and rear blades are found via simulations. The total power captured by the CFD model, ignoring the power generated by the single top and 
bottom blades, can be calculated via multiplying the total vertical force exerted on both front and rear blade by their velocity. $C_{P}$ is calculated by dividing this power by the total wind power passing the swept area of the model.

$C_{P}=\frac{\text { Lift } t_{\text {total }} \times V \lambda}{\frac{1}{2} \rho A^{3}}$

Figure 11 shows the $C_{P}$ achieved by the front, rear and the total blades of the CFD model versus $\lambda$. The arrow between the horizontal solid lines shows the $C_{P}$ achieved by the prototype in the experimental test. The curved lines show the $C_{P}$ predicted by the CFD model (using Equation 10) in different values of $\lambda$. The operating condition of the CFD model is the $\lambda$ at which the maximum $C_{P}$ is achieved $(\lambda=0.2)$. It can be seen that the prototype $C_{P}$ in the experimental test has validated the CFD results. Both models also agree that PowerWindow can generate power with an acceptable $C_{P}$ at very low $\lambda$. This is because of the high $\sigma$ it has compared to the other wind turbines. $C_{P}$ strongly depends on $\lambda$ and stall effect but the operating $\lambda$ has been detected and it has also been explored that this $\lambda$ results in a range of $\alpha$ which are entirely in pre-stall condition. This is evident by considering that stall conditions occurs at $\alpha \sim 21^{\circ}$ as shown in Figure 4 while the operating $\alpha$ is mathematically less than $15^{\circ}$.

Figure 11 shows that the power generation and performance of PowerWindow slightly depends on how the rear blades are located next to the front ones. This results in a sinusoidally varying $C_{P}$, which is not desirable. It is also shown that the maximum $C_{P}$ of the front blades is greater than the rear ones, which is also achieved at a higher $\lambda(=0.25)$ compared to the rear blades $(\lambda=0.175)$. The reasons can be found from the velocity and pressure of the flow passing both models. Detailed explanation is presented in the next sections. 


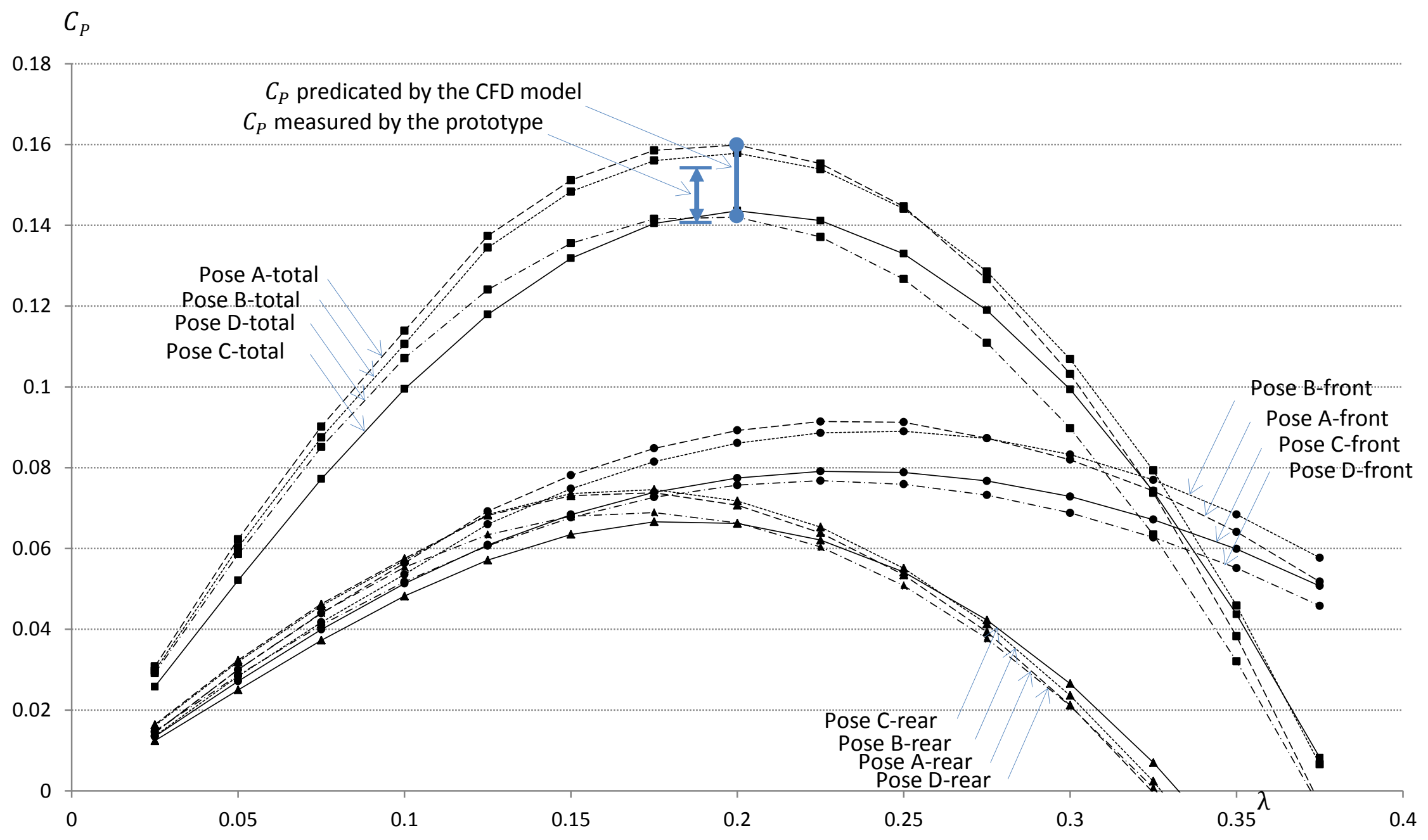

Figure $11 C_{P}$ of the PowerWindow prototype in operating condition (shown by the arrow between two horizontal solid lines in $\lambda \approx 0.2$ ), and the CFD model in $\mathrm{A}, \mathrm{B}, \mathrm{C}$ and $\mathrm{D}$ poses when $\theta_{0}=16^{\circ}$ and $\sigma=0.428$ versus $\lambda$. 


\subsection{Velocity analysis on the flow passing through PowerWindow}

Figures 12 (a), (b), (c) and (d) show the velocity ratio $\left(\mathrm{R}_{V}\right)$ and the wind velocity contours over the PowerWindow model when $\sigma=0.428$ and $\theta_{0}=16^{\circ}$ in operating condition $(\lambda=0.2)$ in poses $\mathrm{A}, \mathrm{B}, \mathrm{C}$ and $\mathrm{D}$ respectively. $R_{V}$ shows the local air velocity ratio to the wind velocity in these figures.

$R_{V}=\frac{V_{\text {local }}}{V_{\text {wind }}}$

As can be seen $R_{V}$ is higher at the top of the front blade and bottom of the rear blade, which is expected to create a low pressure region. Conversely, $R_{V}$ is lower at the bottom and top of the front and rear blades respectively, which results in a high pressure region there. The opposite high and low pressure regions created on the pressure and suctions side of the front and rear blades causes a lift force pushing the front blades upward and the rear ones downward.

Regarding Figure 6 (a), the maximum $R_{V}$ is expected to be greater over the blades located at higher elevations, while Figure 12 shows that $R_{V}$ is generally greater around the bottom blades. This discrepancy may have two reasons:

(i) air flow cannot expand from bottom side and has to pass through the blades, moreover the ramp located at the bottom inlet accelerate the flow toward the blades, which accelerates the incoming flow and increases the velocity magnitude. This increase in the velocity magnitude results in increase in the dynamic pressure and consequently the stagnation pressure (on the pressure side of the blades); and

(ii) vertical velocity of the wind increases when passing above the ramp. Increase in vertical wind velocity also results in increase in the angle of attack $(\alpha)$ and consequently the pressure created on the blades. 


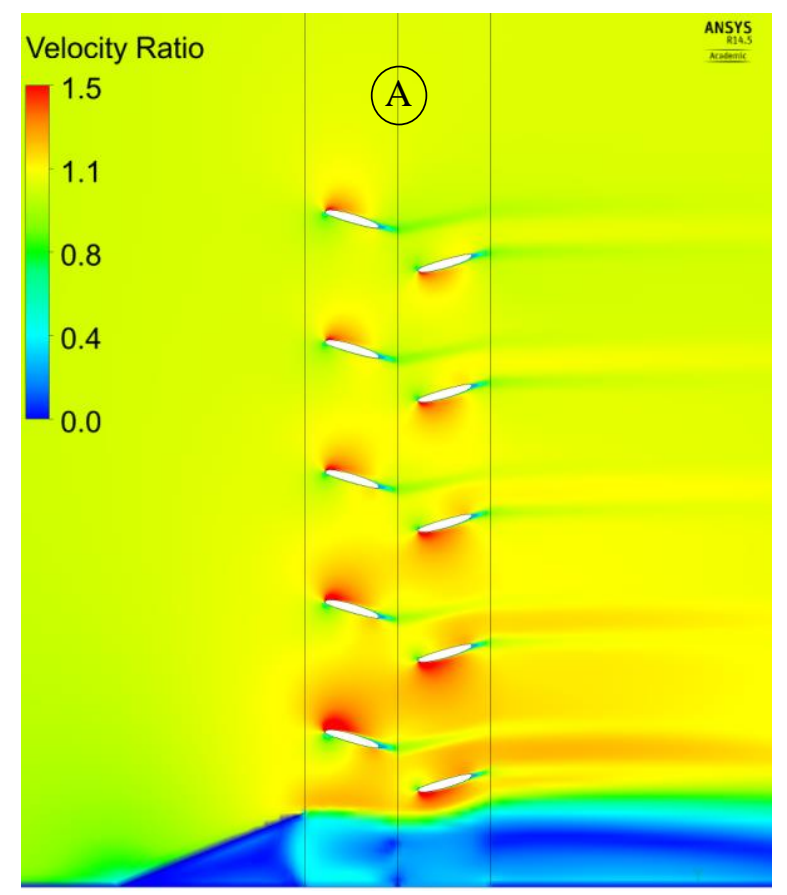

(a)

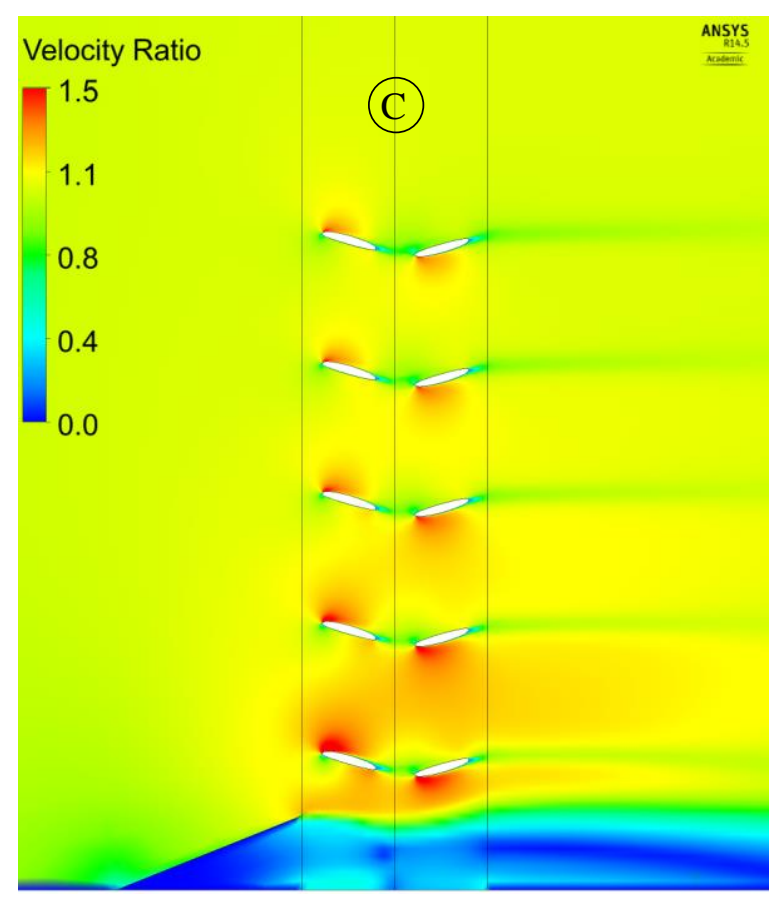

(c)

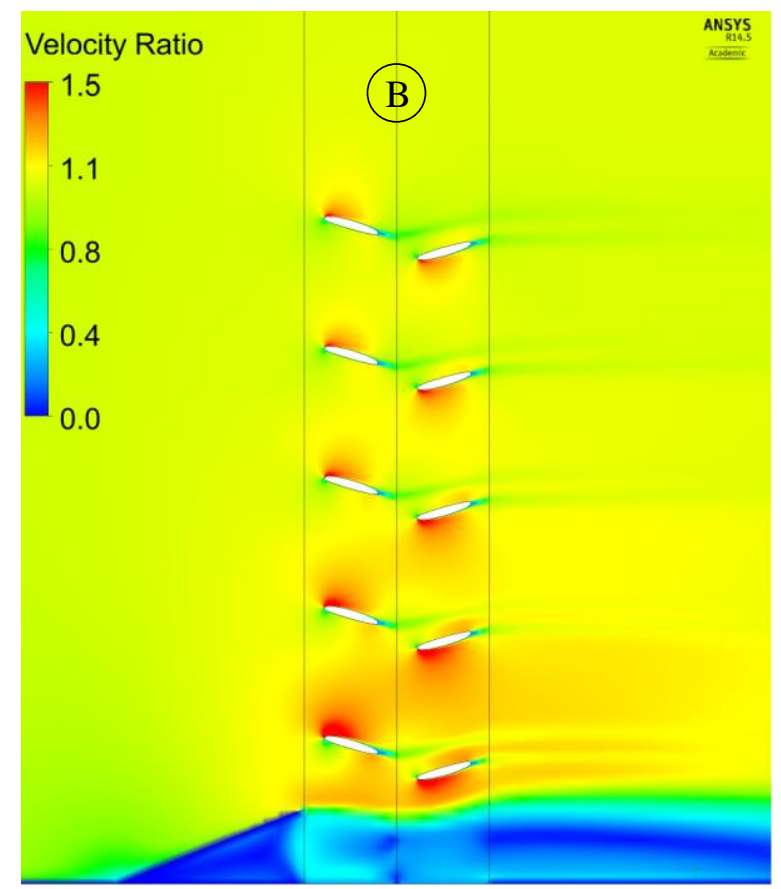

(b)

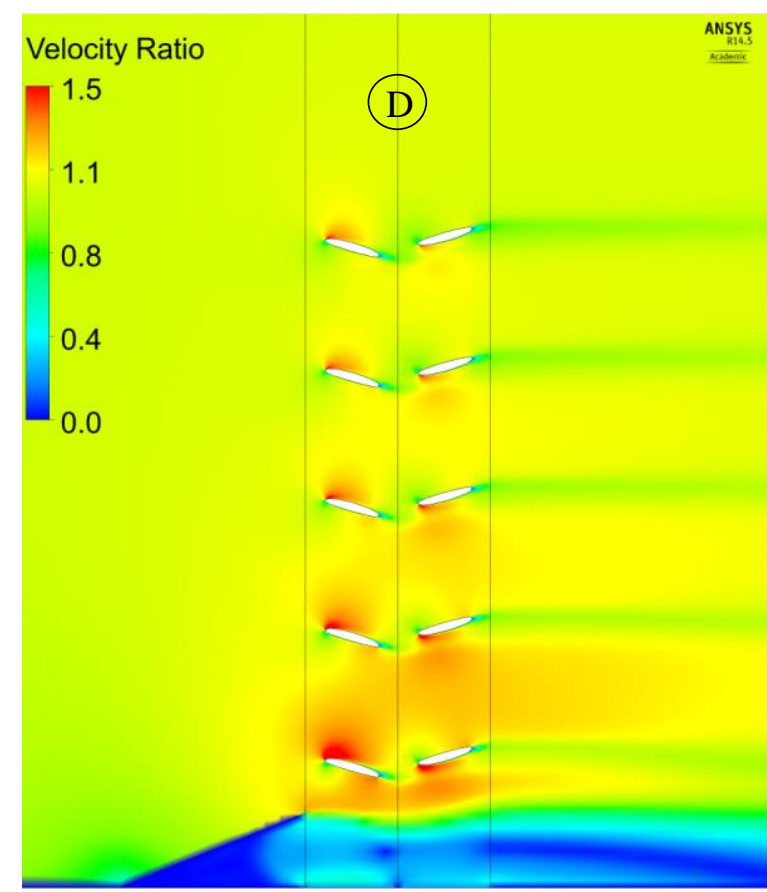

(d)

Figure $12 R_{V}$ contours of the wind passing the PowerWindow CFD model in $\lambda=0.2$ (the operating condition) when $\sigma=0.428$ and $\theta_{0}=16^{\circ}$ in (a) pose A, (b) pose B, (c) pose $\mathrm{C}$ and (d) pose $\mathrm{D}$. 


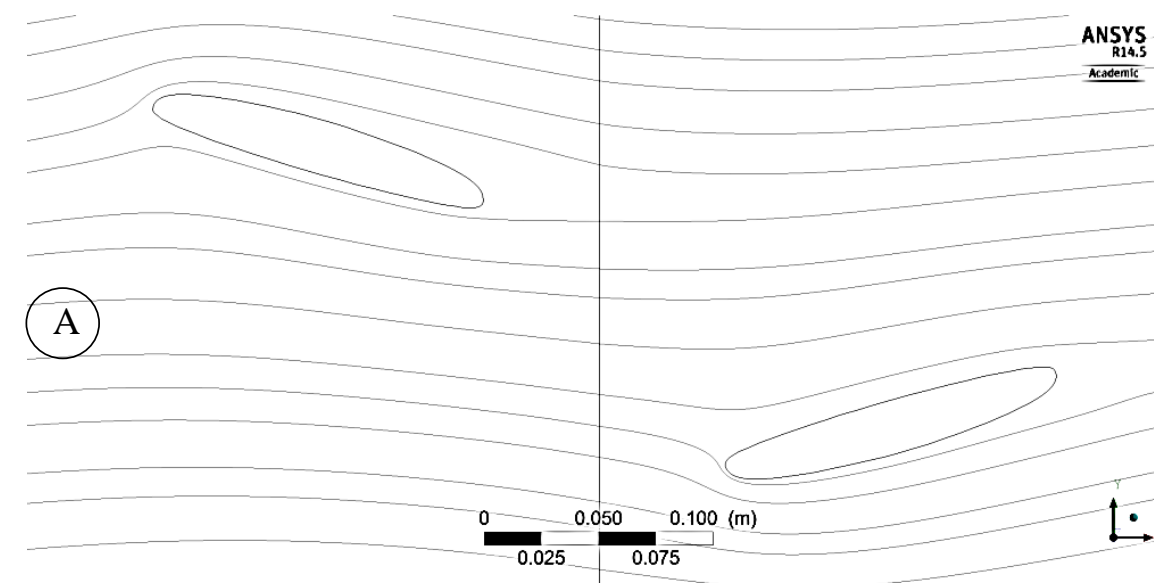

(a)

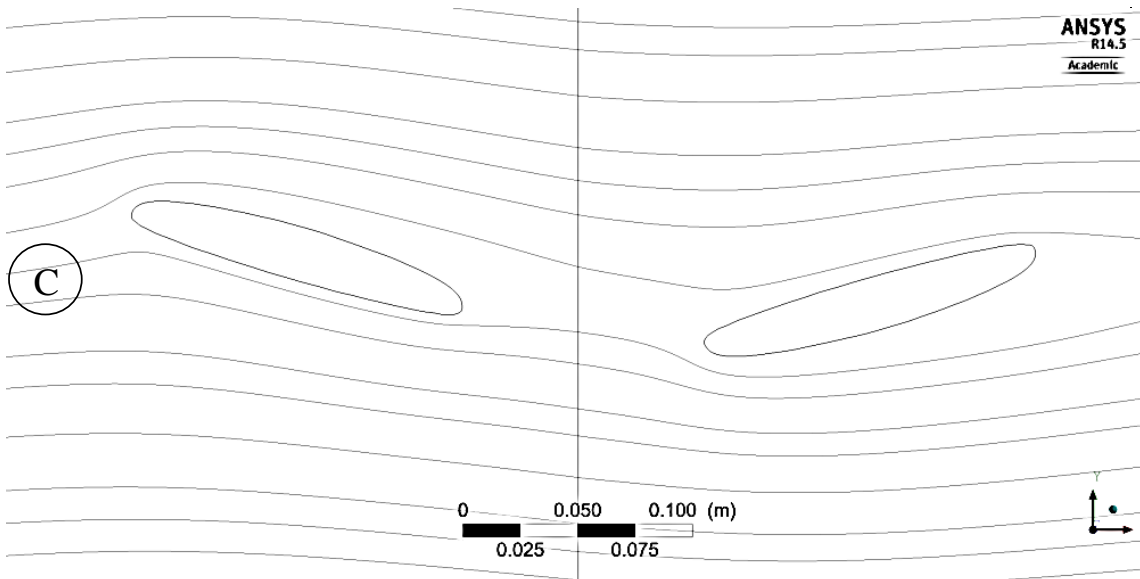

(c)

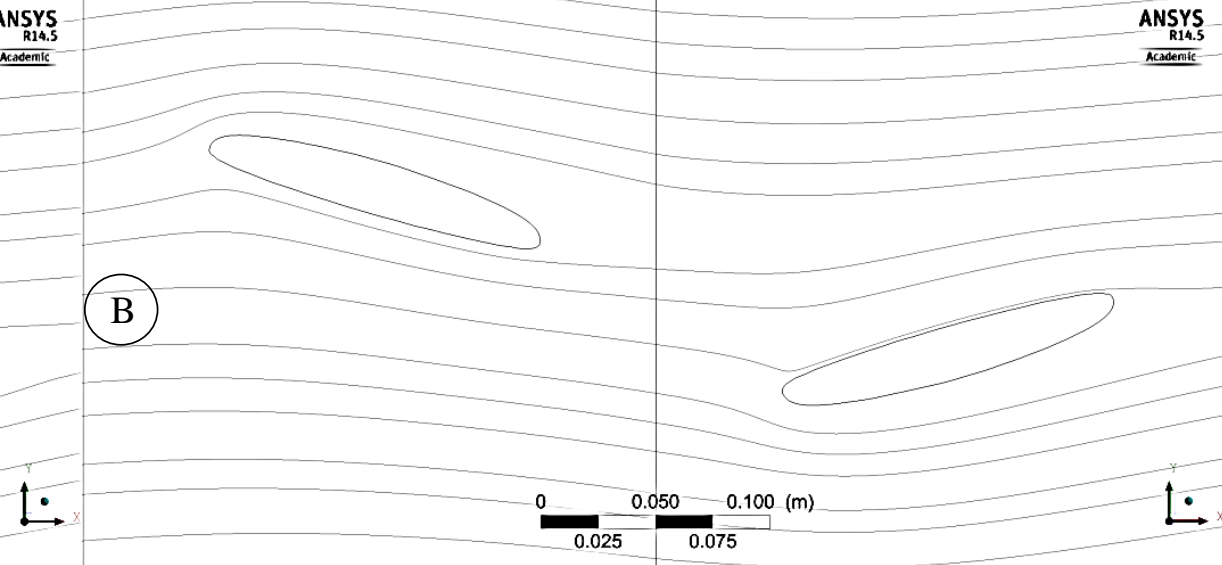

(b)

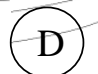

(D)

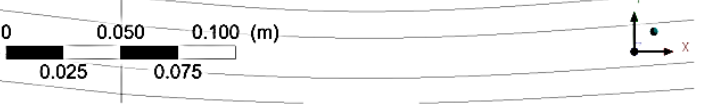

(d)

Figure 13 Streamlines around the the front and rear blades of PowerWindow model for $\lambda=0.2$ (the operating condition) when $\sigma=0.428$ and $\theta_{0}=16^{\circ}$ in $(a)$ pose $A$, (b) pose B, (c) pose C and (d) pose D. 


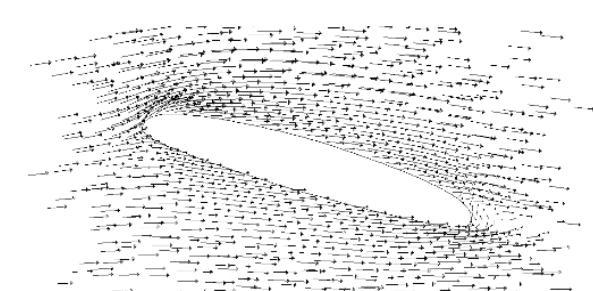

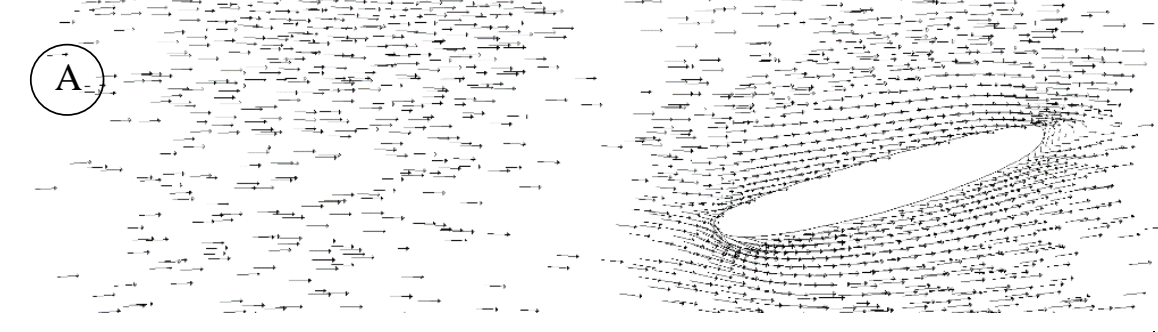

(a)

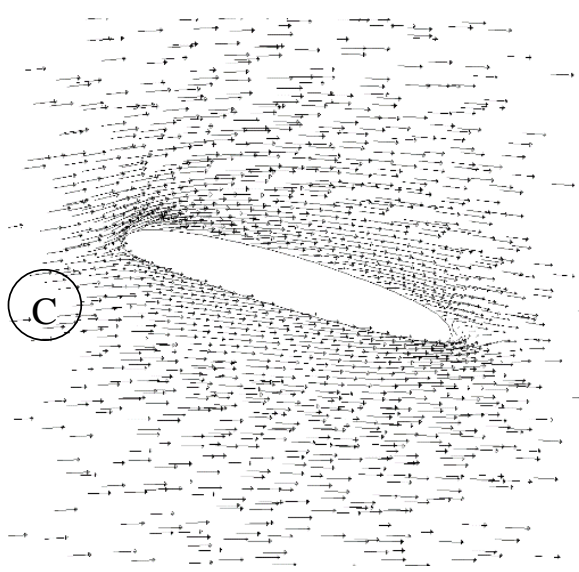

(c)
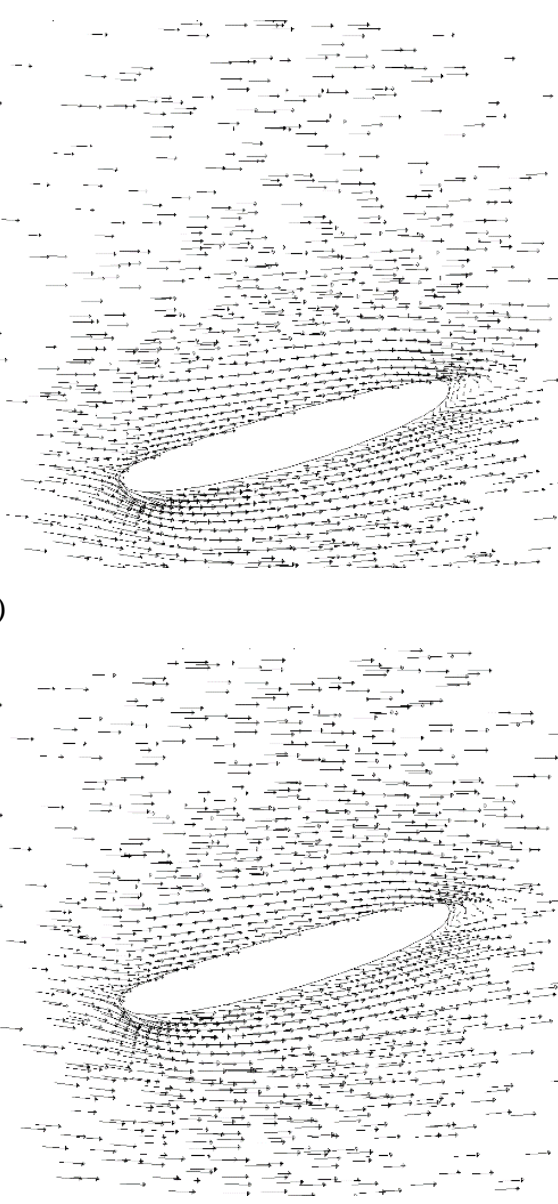

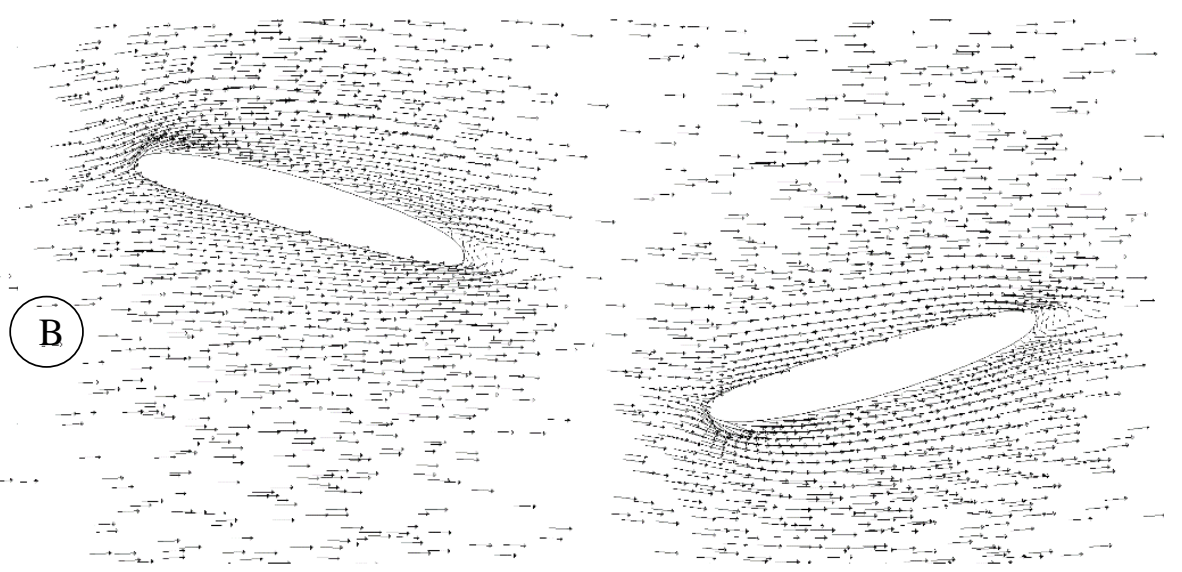

(b)

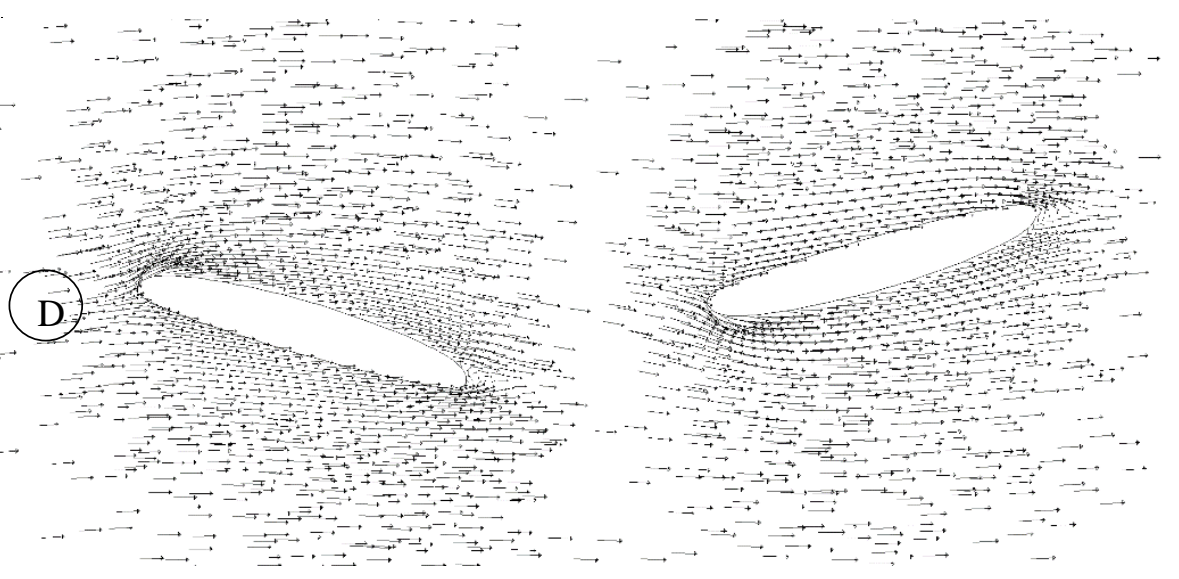

(d)

Figure 14 Velocity vectors around front and rear blades of PowerWindow model for $\lambda=0.2$ (the operating condition) when $\sigma=0.428$ and $\theta_{0}=16^{\circ}$ in $(\mathrm{a})$ pose $A$, (b) pose $B$, (c) pose $C$ and (d) pose $D$. 
A comparison between Figures 12 (a), (b), (c) and (d) indicates that in poses C and D, the rear blades are located in the lower velocity area downstream of the front blades, which adversely affect the wind flow over the rear blades. In this pose, the front blades block the upstream flow reaching the rear ones, which decreases the overall pressure drop of the flow passing through PowerWindow. The lower pressure drop in the airflow results in lower energy extraction from the wind and lower power generation by PowerWindow.

Figure 13 (a), (b), (c) and (d) show the streamlines around the PowerWindow blades for $\lambda=0.2$ (the operating condition) when $\sigma=0.428$ and $\theta_{0}=16^{\circ}$ in pose A, B, C and D respectively. This figure shows that in poses $\mathrm{A}$ and $\mathrm{B}$, the front blades adds a downward velocity to the incoming wind, guiding the incident upstream flow for the rear blades toward them. While in pose $\mathrm{D}$, the front blades have almost no effect on the upstream flow for the rear blades. It can also be seen that in pose $C$, the front blades have slightly blocked the upstream flow of the rear blades. Hence the rear blades in pose $\mathrm{C}$ can be expected to have a lower $C_{P}$.

Figure 14 (a), (b), (c) and (d) show the velocity vectors around the PowerWindow blades for $\lambda=0.2$ (the operating condition) when $\sigma=0.428$ and $\theta_{0}=16^{\circ}$ in poses $\mathrm{A}, \mathrm{B}, \mathrm{C}$ and $\mathrm{D}$ respectively. This figure shows that the ramp has changed the incoming flow direction by creating an upward velocity on the incoming flow and increased $\alpha$ over the front blades. Hence, the ramp increases $\alpha$ over the bottom blades further than the top ones. This figure also shows that the front blades also created a downward velocity on the flow passing them before encountering the rear blades, which changes the flow direction and increases $\alpha$ over the rear ones. The reason that the maximum $C_{P}$ of the front blades has been achieved at higher $\lambda$ (as shown in Figure 11) might be that the overall effect of the ramp on increasing $\alpha$ over the front blades is greater than the effect of the front blades on increasing $\alpha$ over the rear blades. However this can be more clearly seen in the pressure contours over the entire front and rear blades. 


\subsection{Pressure analysis on the flow passing through PowerWindow}

Figures 15 (a), (b), (c) and (d) show the pressure contours of the wind passing over the middle blades of the PowerWindow model when $\sigma=0.428$ and $\theta_{0}=16^{\circ}$ in operating condition $(\lambda=$ 0.2 ) respectively in poses $A, B, C$ and $D$ respectively. Pressure contours are shown in terms of the surface pressure coefficient $\left(C_{S P}\right)$ which shows the ratio of the local air pressure to the dynamic pressure of the free stream velocity (Equation 12). Figure 16 (a) and (b) show the $C_{S P}$ value over these blades. Figure 13 and 14 agree that the power generated by PowerWindow in poses A and B is higher than $\mathrm{C}$ and $\mathrm{D}$ due to the higher pressure created on their pressure side and lower pressure created on their suction side.

$C_{S P}=\frac{P_{\text {static }}}{0.5 \rho V^{2}}$

Figure 15 also shows that the pressure distribution created on the rear blades are affected by the position of the front ones so that, contrary to the front blades, the minimum $C_{S P}$ of the rear blades in poses B and D are lower than in poses A and C. However, vertical force exerted on the front and rear blades are expected to be almost equal in Figures 15 and 16, while Figure 11 shows that the power generation performance of the front blades in $\lambda \geq 0.15$ is greater than the rear ones. The reason can be explained by investigating the pressure distribution over the entire front and rear blades predicted by the CFD model.

As can be seen in Figures 17 (a), static pressure of the incoming flow is expected to decrease in two stages: (i) when passing the front blades and; (ii) when passing the rear ones. However, regarding the power generation contribution of the front and rear blades shown in Figures 11, the major pressure drop is expected to happen at the front blades which means that $P_{2}-P_{3}>P_{4}-P_{5}$. Further supporting evidence can be found in Figure 17 (b) which shows the pressure contours around the CFD model (when $\sigma=0.428, \theta_{0}=16^{\circ}$ ) at the operating condition $(\lambda=0.2$ ). 

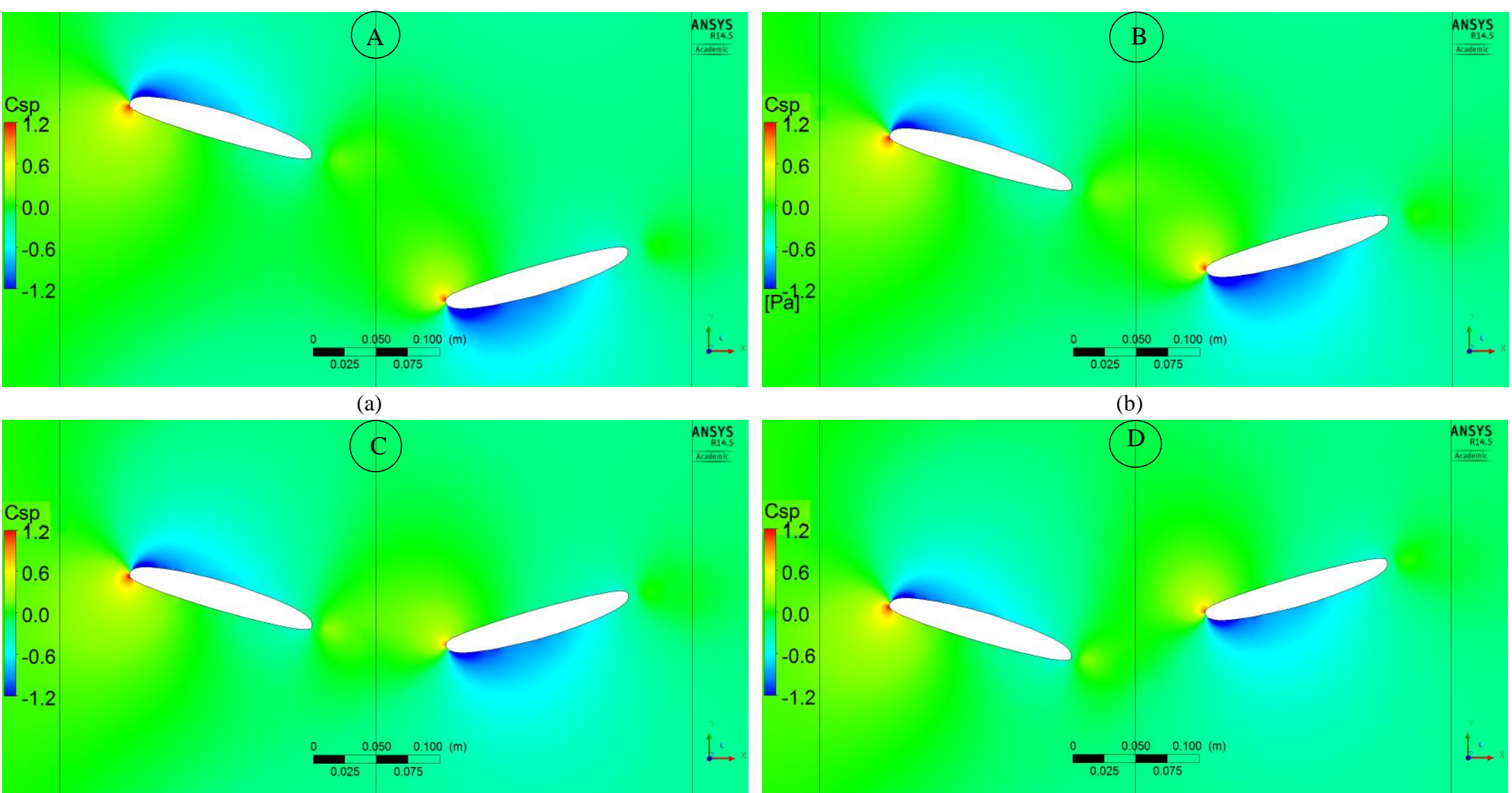

(c)

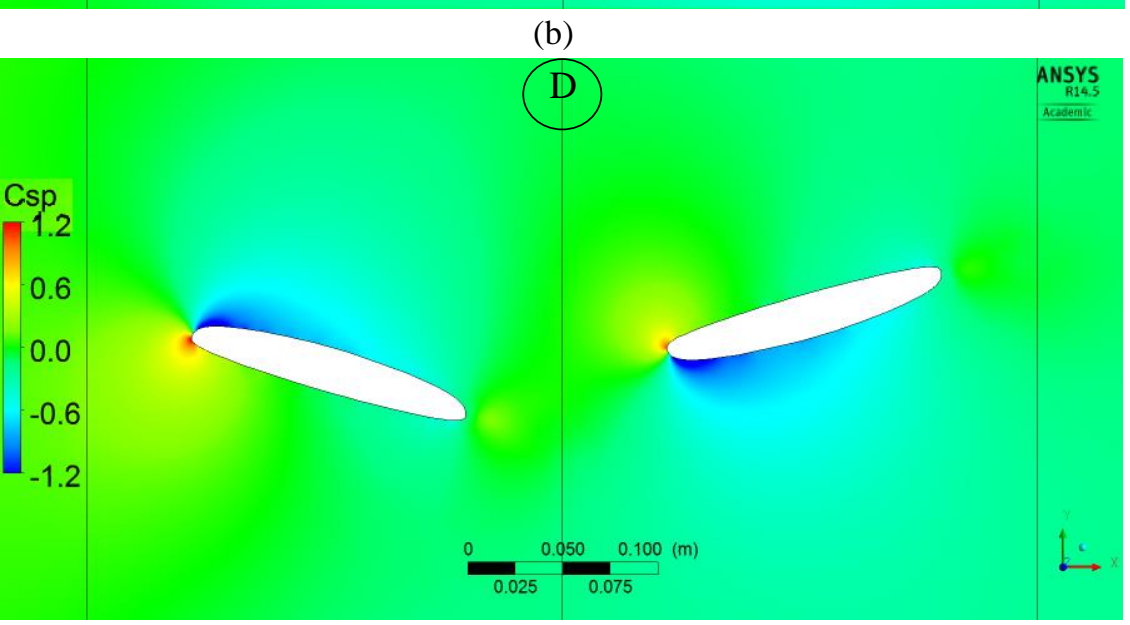

(d)

Figure 15 Static pressure over middle blades of PowerWindow CFD model for $\lambda=0.2$ (the operating condition) when $\sigma=0.428$ and $\theta_{0}=16^{\circ}$ in (a) pose A, (b) pose $\mathrm{B},(\mathrm{c})$ pose $\mathrm{C}$ and (d) pose $\mathrm{D}$. 


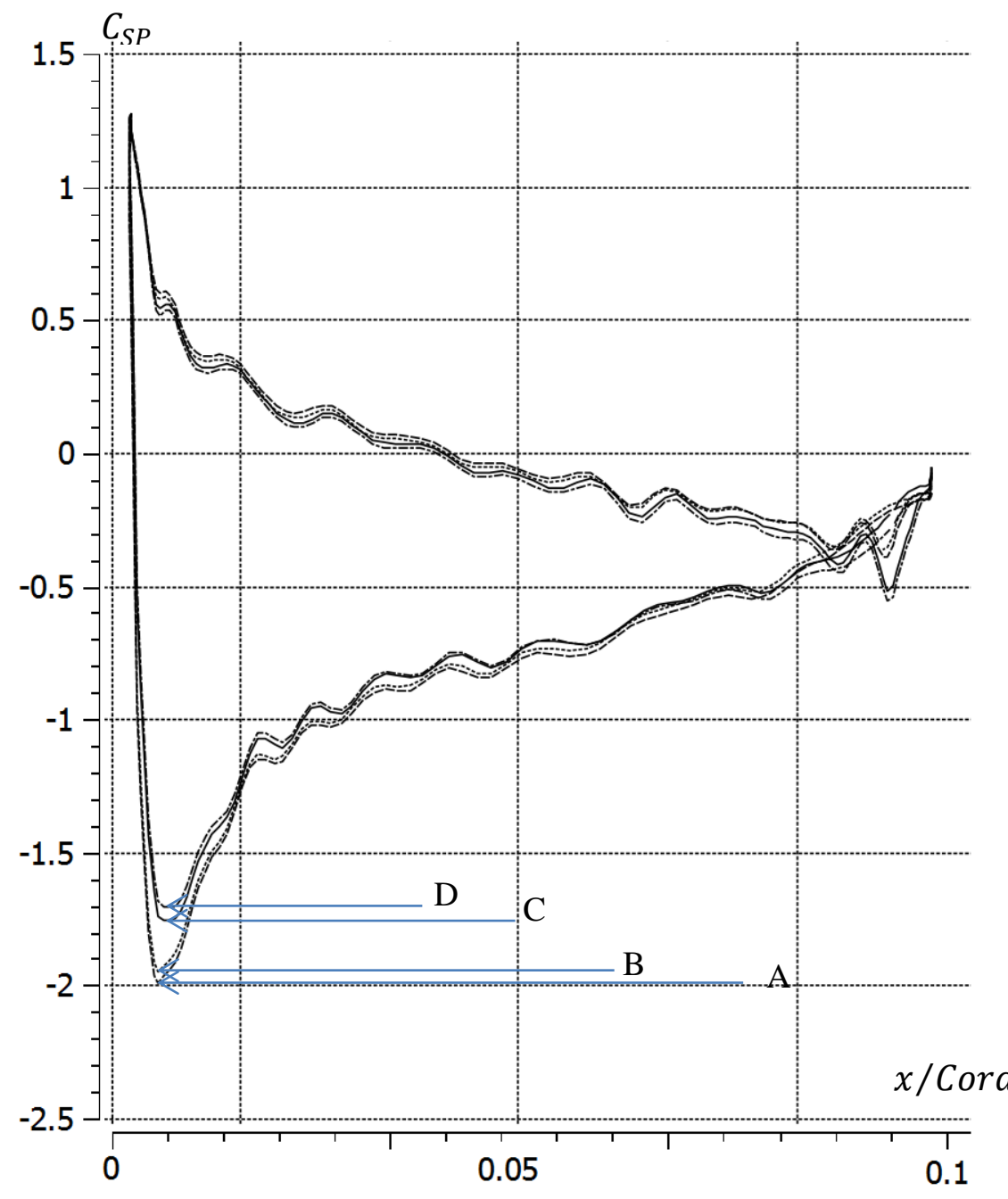

(a)

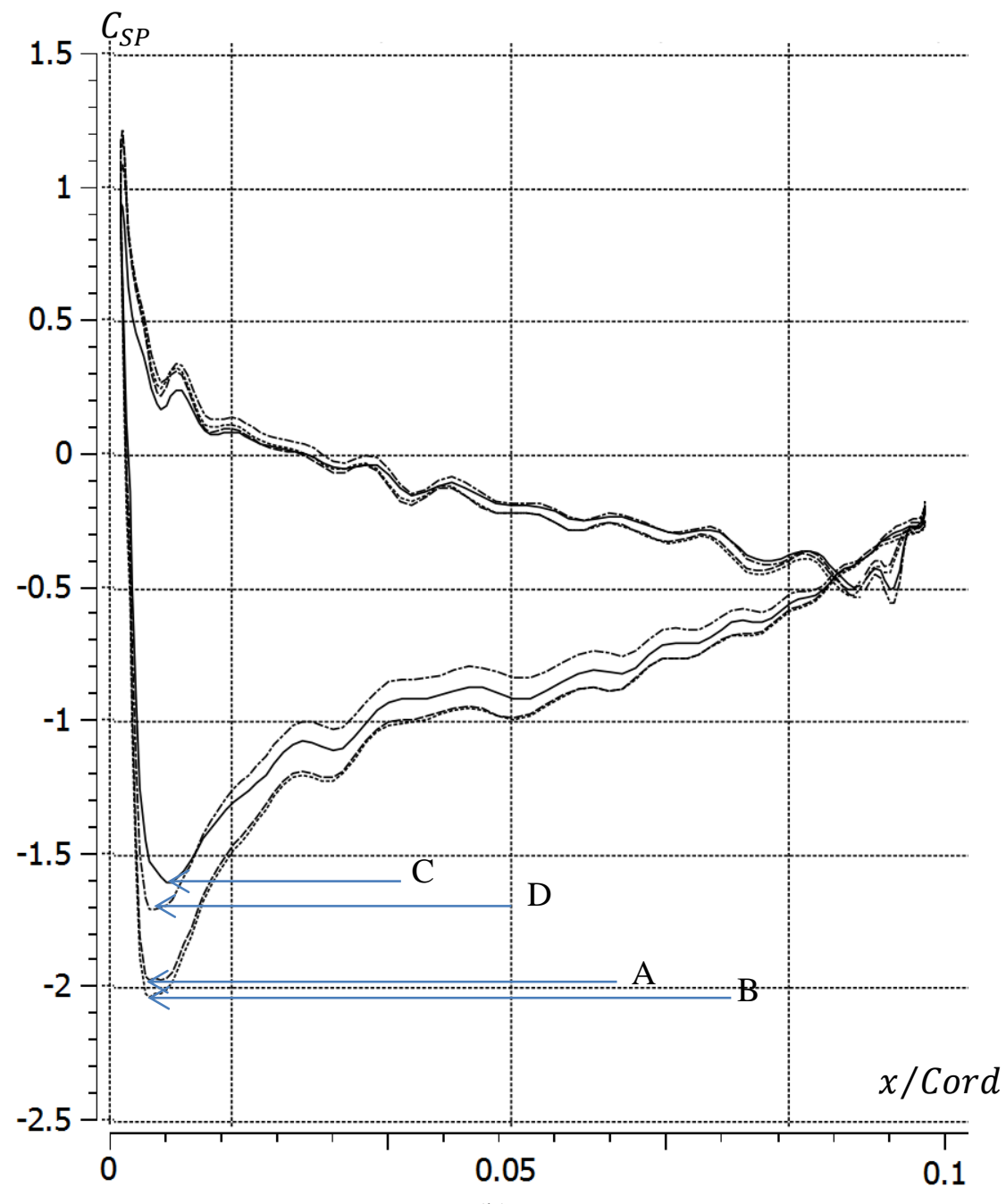

(b)

Figure $16 C_{S P}$ distribution over (a) front and (b) rear middle blades of PowerWindow CFD model, when $\sigma=0.428, \theta_{0}=16^{\circ}$ and $\lambda=0.2$ through the chord length. 


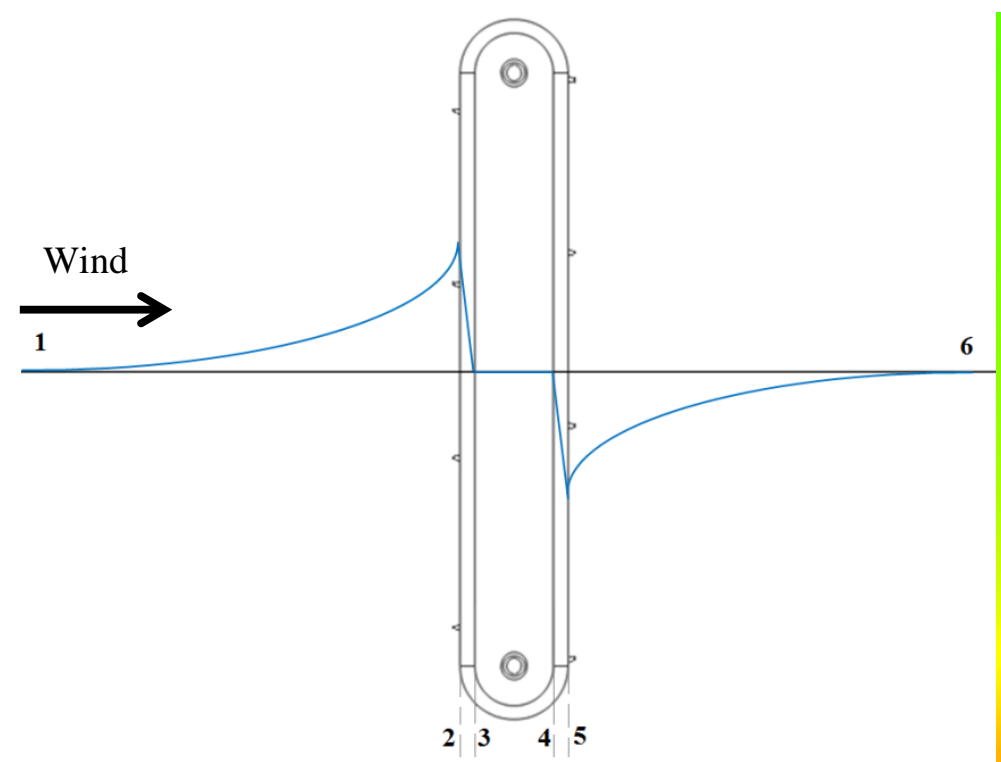

(a)

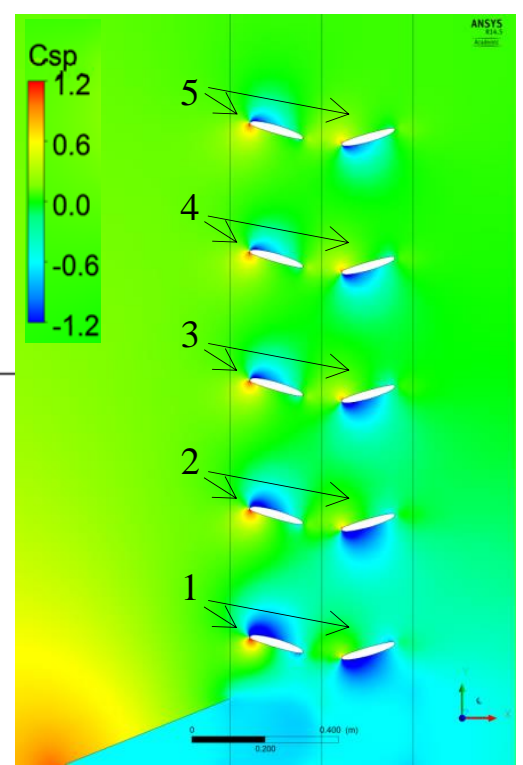

(b)

Figure 17 (a) Air static pressure when passing through PowerWindow, (b) $\mathrm{C}_{\mathrm{SP}}$ contours of the wind passing through the PowerWindow model when $\sigma=0.428, \theta_{0}=16^{\circ}$ and $\lambda=0.2$.

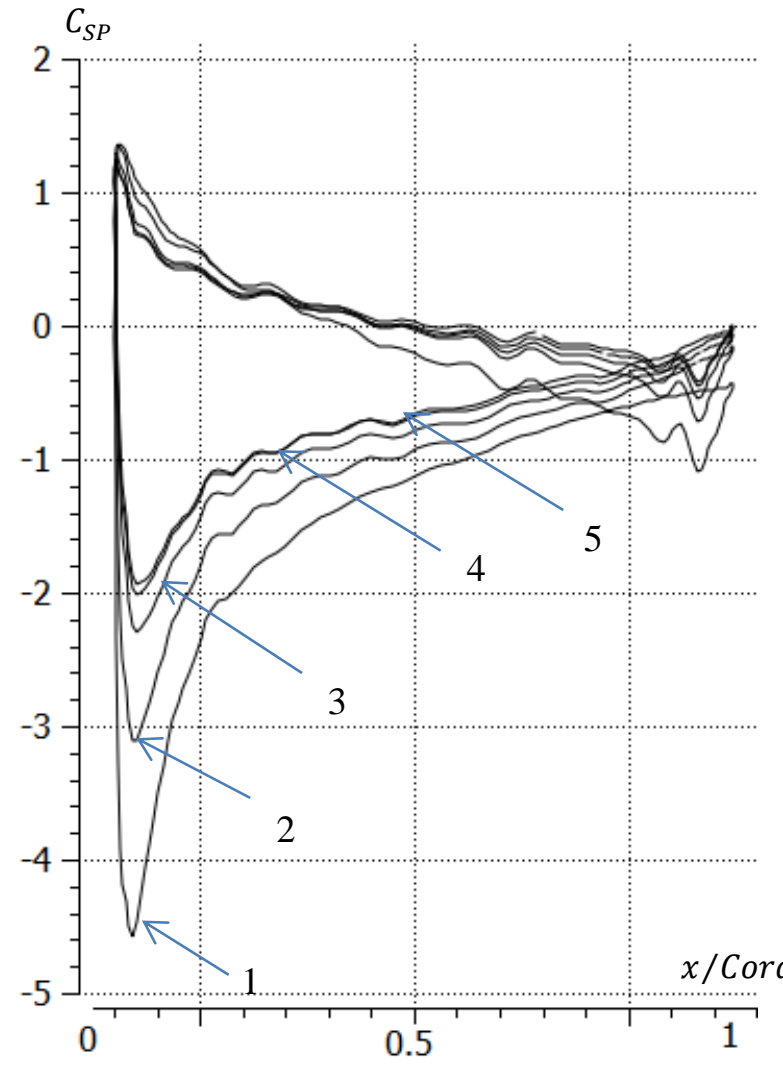

(a) Front blades

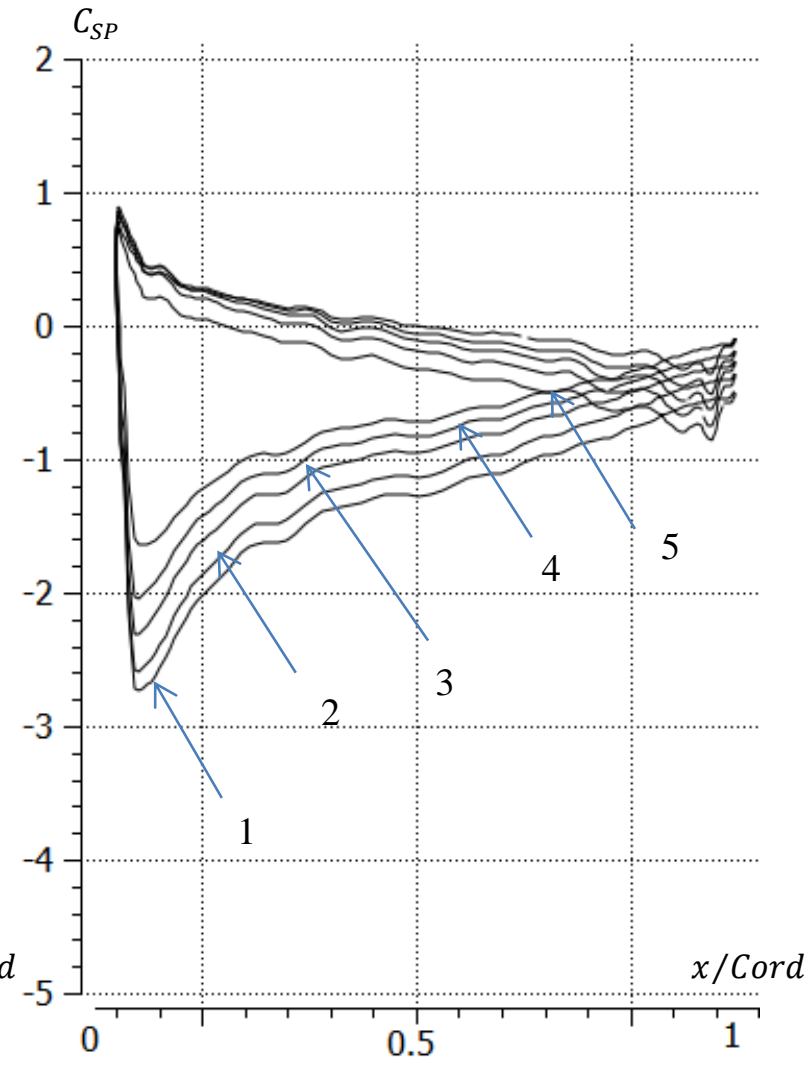

(b) Rear blades

Figure $18 C_{S P}$ distribution over (a) front and (b) rear blades of PowerWindow model, when $\sigma=0.428$, $\theta_{0}=16^{\circ}$ and $\lambda=0.2$ through the chord length. 
Figure 17 (b) shows that a high pressure region is created on the pressure side of the front blades, which is greater than the same region created on the rear blades. On the other hand, the low pressure region created on the suction side of the rear blades is greater than the same region created on the front blades. Hence, to clarify the contribution of the front and rear blades in power generation, pressure distribution on the front and rear blades are investigated and plotted in term of $C_{S P}$ through their chord line. Figures 18 (a) and (b) show the $C_{S P}$ distribution over the front and rear blades when $\sigma=0.428, \theta_{0}=16^{\circ}$ and $\lambda=0.2$ (which is its operating $\lambda$ ).

Figure 18 shows that $C_{S P}$ on the suction side of the front blades is indeed much lower than on the rear blades. Moreover, $C_{S P}$ on the pressure side of the front blades is higher than on the rear ones. As a result the pressure difference between the pressure and suction sides of the front blades is greater than the rear blades and the lift force created on the front blades is greater than the rear blades. This result confirms that the front blades have greater contribution in power generation compared to the rear ones, which was also shown in Figure 11.

In Figure 18 shows the pressure distributions over the blades which have numbered 1 to 5 from bottom to top. The pressure distributions show that as the blades move close to the ramp the subatmospheric pressure on their suction side is lower, so that the minimum $C_{S P}$ is almost -4.5 for the front blade number 1 as can be seen in Figure 18 (a), and $C_{S P}$ is almost -2.5 for the rear blade number 1 as can be seen in Figure 18 (b). This shows that increasing $\alpha$ results in a significant increase in the lift force exerted on the blades and consequently enhancing the power generation, which is also achievable by increasing $\theta_{0}$.

One more noticeable point in Figures 18 (a) and (b) is that the $C_{S P}$ distribution crosses the zero pressure line on the pressure side of the blades, so that $C_{S P}$ has a positive value at the leading edge 
of the blades but a negative value at their trailing edge. The reason is that the flow decelerates when reaching the leading edge and its pressure increases almost to the stagnation pressure. While the flow velocity increases to a value greater than the incoming velocity when reaching the trailing edge. As a result, the pressure decreases to a value lower than the incoming wind (atmospheric) pressure.

\section{Conclusion}

A modular linear wind generator, PowerWindow, was introduced and its power generation investigated using CFD simulations. An experimental test on a PowerWindow prototype has also been done and the test results utilized to validate the CFD simulation results. Experimental test and the CFD simulations showed that PowerWindow can generate electricity with $C_{P}$ (coefficient of performance) of 0.15 at $\lambda$ (tip speed ratio) of 0.2 , which is a low linear velocity ratio and not achievable in most conventional wind turbines with the same size. The low $\lambda$ of PowerWindow operating condition makes it a safe power generator in built environments. The $C_{P}$ of PowerWindow was found to slightly depend on how the rear blades are located next to the front ones. The flow mechanism during the passage over the front and rear blades was investigated and the results show that the front blades make a higher contribution to power generation. Evidently the maximum power generated by the front blades, which were exposed to a higher $\alpha$ (angle of attack), was achieved at a higher $\lambda(=0.25)$ compared to the rear blades $(\lambda=0.175)$. This shows that increasing $\alpha$ could result in a significant increase in the power generation of PowerWindow. This can be achieved by optimizing $\theta_{0}$ (design angle) and other flow enhancement strategies, which can be investigated in further studies. 


\section{Nomenclature}

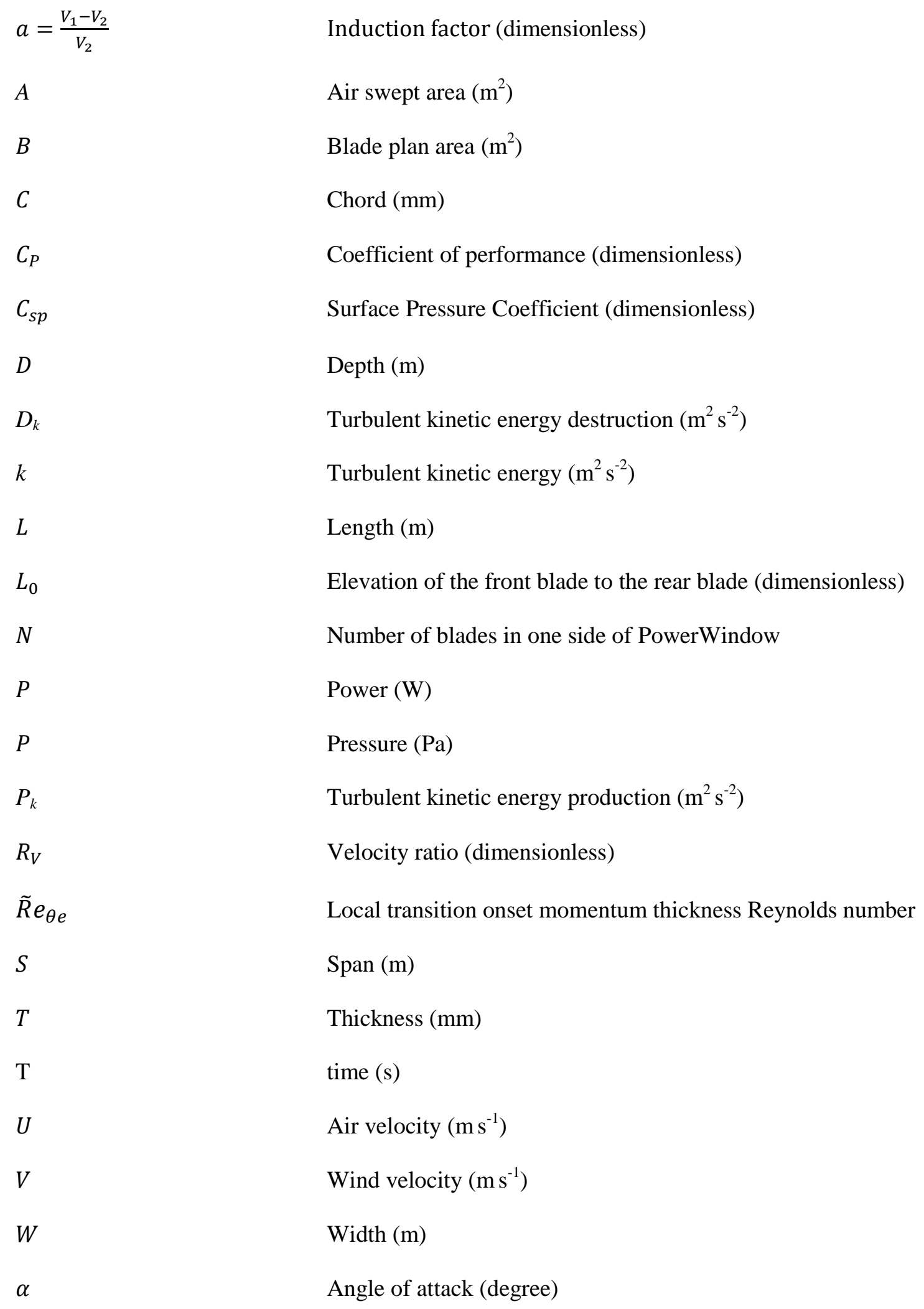

Chord (mm)

Coefficient of performance (dimensionless)

Surface Pressure Coefficient (dimensionless)

Depth (m)

Turbulent kinetic energy destruction $\left(\mathrm{m}^{2} \mathrm{~s}^{-2}\right)$

Turbulent kinetic energy $\left(\mathrm{m}^{2} \mathrm{~s}^{-2}\right)$

Length (m)

Elevation of the front blade to the rear blade (dimensionless)

Number of blades in one side of PowerWindow

Power (W)

Pressure $(\mathrm{Pa})$

Turbulent kinetic energy production $\left(\mathrm{m}^{2} \mathrm{~s}^{-2}\right)$

Velocity ratio (dimensionless)

Local transition onset momentum thickness Reynolds number

Span (m)

Thickness (mm)

time (s)

Air velocity $\left(\mathrm{m} \mathrm{s}^{-1}\right)$

Wind velocity $\left(\mathrm{m} \mathrm{s}^{-1}\right)$

Width (m)

Angle of attack (degree) 


$\begin{array}{ll}\theta_{0} & \text { Design angle (dimensionless) } \\ \sigma & \text { Solidity (dimensionless) } \\ \alpha & \text { Expansion angle (degree) } \\ \gamma & \text { Distance to nearest wall (m) } \\ \gamma_{e f f} & \text { Effective intermittency (dimensionless) } \\ \mu & \text { Molecular viscosity (Pa s) } \\ \mu_{t} & \text { Eddy viscosity (Pa s) } \\ \rho & \text { Air density (kg m }{ }^{-3} \text { ) } \\ \lambda & \text { Linear velocity ratio (dimensionless) }\end{array}$




\section{References}

[1] S. Eriksson, H. Bernhoff, M. Leijon, Evaluation of different turbine concepts for wind power, Renewable and Sustainable Energy Reviews, 12 (2008) 1419-1434.

[2] F.L. Ponta, J.J. Seminara, A.D. Otero, On the aerodynamics of variable-geometry oval-trajectory Darrieus wind turbines, Renewable Energy, 32 (2007) 35-56.

[3] M. Islam, D.S.K. Ting, A. Fartaj, Aerodynamic models for Darrieus-type straight-bladed vertical axis wind turbines, Renewable and Sustainable Energy Reviews, 12 (2008) 1087-1109.

[4] F.L. Ponta, L.I. Lago, Analysing the suspension system of variable-geometry oval-trajectory (VGOT) Darrieus wind turbines, Energy for Sustainable Development, 12 (2008) 5-16.

[5] A.D. Otero, F.L. Ponta, On the structural behaviour of variable-geometry oval-trajectory Darrieus wind turbines, Renewable Energy, 34 (2009) 827-832.

[6] PowerWindow, in, Farzad Safaei, 2015, pp. https://youtu.be/XM5SFx-IJJ0.

[7] K. Appa, Energy innovations small grant (EISG) program (counter rotating wind turbine system), EISG Final Report, California, US, (2002).

[8] S. Lee, H. Kim, E. Son, S. Lee, Effects of design parameters on aerodynamic performance of a counter-rotating wind turbine, Renewable Energy, 42 (2012) 140-144.

[9] B. Hwang, S. Lee, S. Lee, Optimization of a counter-rotating wind turbine using the blade element and momentum theory, Journal of Renewable and Sustainable Energy, 5 (2013).

[10] S. Lee, H. Kim, S. Lee, Analysis of aerodynamic characteristics on a counter-rotating wind turbine, Current Applied Physics, 10 (2010) S339-S342.

[11] Birdon, in, Birdon, 2014, pp. http://birdon.com.au/.

[12] Monash University Wind Tunnel, in, 2013, pp.

http://www.eng.monash.edu.au/mechanical/windtunnel/facilities.html.

[13] D. Wei, Z. Feng, Loading Analysis and Strength Calculation of Wind Turbine Blade Based on Blade Element Momentum Theory and Finite Element Method, in: Power and Energy Engineering Conference (APPEEC), 2010 AsiaPacific, 2010, pp. 1-4.

[14] R. Lanzafame, S. Mauro, M. Messina, Wind turbine CFD modeling using a correlation-based transitional model, Renewable Energy, 52 (2013) 31-39.

[15] T. O’Doherty, A. Mason-Jones, D.M. O’Doherty, P.S. Evans, C. Wooldridge, I. Fryett, Considerations of a horizontal axis tidal turbine, in: Proceedings of the ICE - Energy, 2010, pp. 119-130.

[16] F.P. Incropera, P. David, De Witt, Fundamentals of heat and mass transfer, 4 (1990).

[17] M. Shives, C. Crawford, Developing an empirical model for ducted tidal turbine performance using numerical simulation results, Proceedings of the Institution of Mechanical Engineers, Part A: Journal of Power and Energy, (2011).

[18] F.R. Menter, Review of the shear-stress transport turbulence model experience from an industrial perspective, Int. J. Comput. Fluid Dyn., 23 (2009) 305-316.

[19] S.M. El-Behery, M.H. Hamed, A comparative study of turbulence models performance for separating flow in a planar asymmetric diffuser, Computers \& Fluids, 44 (2011) 248-257. 
[20] C.U. Buice, J.K. Eaton, Experimental Investigation of Flow Through an Asymmetric Plane Diffuser, Journal of Fluids Engineering, 122 (2000) 433-435.

[21] S.A.H. Jafari, B. Kosasih, Flow analysis of shrouded small wind turbine with a simple frustum diffuser with computational fluid dynamics simulations, Journal of Wind Engineering and Industrial Aerodynamics, 125 (2014) 102 110.

[22] S.A. Jafari, B. Kosasih, Analysis of the power augmentation mechanisms of diffuser shrouded micro wind turbine with computational fluid dynamics simulations, Wind and Structures, 19 (2014) 199-217.

[23] Gambit, in, U.S. Army Research Laboratory DoD Supercomputing Resource Center, 2015, pp. http://www.arl.hpc.mil/software/description.html?sw=Gambit. 